\title{
The Impact of UK Household Overconfidence in Public Information on House Prices*
}

\author{
Soosung Hwang ${ }^{\dagger}$ \\ Sungkyunkwan University \\ Youngha $\mathrm{Cho}^{\#}$ \\ Oxford Brookes University \\ Jinho Shin \\ Sungkyunkwan University
}
* We would like to thank participants at the 52nd AREUEA Annual Conference and the AREUEA International Conference for helpful comments.

† Department of Economics, Sungkyunkwan University, 25-2 Sungkyunkwan-Ro, Jongno-gu, Seoul 110-745, South Korea. Tel: +82 (0)2 760 0489, Fax: +82 (0)2 744 5717, Email: shwang@skku.edu.

\# Corresponding author, School of Built Environment, Oxford Brookes University, Gipsy Lane, Oxford, OX3 OBP, UK. Tel: +44(0)1865 483941, Fax: +44(0)1865 483927, Email: ycho@brookes.ac.uk

- Department of Economics, Sungkyunkwan University, 25-2 Sungkyunkwan-Ro, Jongno-gu, Seoul 110-745, South Korea. Tel: +82 (0)2 3788 2334, Fax: +82 (0)2 3788 2350, Email: jinho.shinn@gmail.com. 


\title{
The Impact of UK Household Overconfidence in Public Information on House Prices
}

\author{
We investigate if house prices are affected by overconfidence of households who \\ predict house prices using imperfect public information about economic outlook. For \\ this purpose, we develop a new measure of household overconfidence in the Bayesian \\ framework. For the three variables we test - changes in consumption, stock returns, and \\ changes in human capital, we find that UK households were overconfident about the \\ signals of consumption regardless of regions. However, households in London were \\ overconfident about the signals of stock markets whereas those remote from London \\ were overconfident about the signals of human capital. The results of household \\ overconfidence appear positive in the UK housing market for our sample period from \\ 1980 to 2018 , in particular, $0.5 \%$ per quarter in London.
}

Keywords: Overconfidence; Public Signals; Households; House Prices; Bayesian Updating

JEL classification: R3, G12 


\section{Introduction}

The impacts of house price boom-busts on consumption last nearly twice as long and are nearly twice as large as those of equity price busts (Helbling and Terrones, 2003). Moreover, house price busts have preceded more than two thirds of systemic banking crises. ${ }^{1}$ Given the importance of the housing sector in the real economy, various explanations have been proposed for the repeated failure in house pricing: for example, irrational bubbles (Escobari et al., 2012; Kivedal, 2013), media hype (Case and Shiller, 2003; Shiller, 2005), anchoring (Clayton et al. 2001), momentum and herd behaviour (Case et al., 2003; Shiller, 2005; Hott, 2012) among others. However, these studies do not show which macroeconomic variables contribute to boom-busts in house prices, or the dynamics of boom-bust cycles in different regions.

In this study, we investigate whether household overconfidence about publically available information contributes to mispricing in housing markets. Our study is characterised by a few distinct features. First, we focus on overconfidence because it is the most significant cognitive bias (Kahneman, 2011; Daniel and Hirshleifer, 2015). In housing market households are likely to be overconfident because they are not well informed and have limitations in processing information (Gervais and Odean, 2001). Second, we investigate the effects of public information on house prices in a similar way that people miscalibrate the precision of private information (Daniel et al, 1998). ${ }^{2}$ The literature in asset pricing suggests that only private information matters in asset pricing because all public information should be

\footnotetext{
${ }^{1}$ http://www.imf.org/external/np/speeches/2014/060514.htm.

2 Overconfidence has been interpreted differently in the literature. Moore and Healy (2008) define overconfidence in three different ways: as over-placement, over-estimation, and over-precision. Over-placement (better-than-average) tends to be found in easy tasks, whereas overestimation is closely related to optimism with respect to expectations.
} 
fully and instantaneously reflected in prices. However, in housing markets where valuations are not as straightforward as those in financial markets, particularly due to the short-sale restriction, illiquidity, heterogeneity in residential properties (Okunev et al., 2000), and their role as consumption good (Shiller, 2006), public information can still be used to predict house prices (e.g., Clayton, 1998).

We test three macroeconomic variables instead of an arbitrarily large number of variables. The variables are changes in consumption, stock returns, and changes in human capital that we obtain under the assumption that households optimize their consumption using the Epstein and Zin $(1989,1991)$ utility. The Epstein-Zin utility incorporates decision makers' willingness to change consumption over time and across different states of the world, and thus gives us a flexible pricing model with two variables, i.e., consumption and the wealth portfolio. We further divide the wealth portfolio into stock and human capital because human capital forms a substantial part of the wealth portfolio in the economy (Mayers, 1972; Jagannathan and Wang, 1996). ${ }^{3}$

Our Bayesian approach replicates the decision process that households follow to predict house prices: households, implicitly or explicitly, forecast economy using noisy public signals and predict house prices. We propose a novel method to measure overconfidence of households who use imperfect information about the three variables, which is referred to as "noisy signals" in this study. Our method compares the responses of observed property returns to the three variables (signals without noise), with those to the noisy signals

\footnotetext{
${ }^{3}$ See the Appendix for the pricing model we drive from the Epstein-Zin utility. The popular hyperbolic absolute risk aversion class of utility functions is limited, as it does not properly distinguish between intertemporal substitution and risk aversion, and thus cannot explain a large shift in consumption over time caused by a small increase in the interest rate (or discount factor) when the elasticity of intertemporal substitution in consumption is large.
} 
of these three variables. If households miscalibrate the precision of noisy signals because of their overconfidence, observed property returns are affected by the noisy signals more than by the variables themselves, leading to boom-busts in house prices.

Our main research questions are as follows: are households overconfident about the noisy public signals they use to predict house prices?; to what signals do they respond irrationally?; does household overconfidence show any geographical differences over time? We answer these questions using the residential property returns of the 12 UK regions for our sample period from 1980 to 2018.

The empirical results show that UK households are overconfident about the noisy signals. First, household overconfidence contributes to boom-bust price patterns in the UK housing market. They were significant and positive from the mid-1980s to the end of the 1980s and from the mid-1990s to the Brexit decision in 2016, except for a few years after the 2008 financial crisis. The effects were negative when housing markets were in recession or during financial crises.

Second, household overconfidence also shows regional differences. Among the three variables, UK households are overconfident about noisy signals for consumption changes regardless of regions. However, households in northern regions (e.g., North West and Scotland) were more likely to be overconfident in signals about human capital changes, whereas households in London and neighbouring regions were more overconfident in signals about financial markets than in signals about human capital changes. As a possible explanation, we propose a cognitive bias that people tend to believe that they are more informed about the familiar than the unfamiliar (Huberman, 2001; Riff and Yagil, 2016). For example, households in London, who are familiar with financial markets, weigh signals of financial markets too strongly because they believe that they are better informed than others. 
The dynamics of household overconfidence across regions affect house prices differently. Households in London expected $0.5 \%$ per quarter higher than that of rational households during our sample period. The difference was large in the 1980s, but not in the 2010s. During the 2010s, most UK regions were positively affected by household overconfidence until the Brexit decision in 2016. Since the Brexit decision, households in London and Scotland appeared too sensitive to negative signals, lowering expected house price growth by more than $-0.6 \%$ per quarter.

Our study differs from previous studies that focus on the macroeconomic determinants of house prices (Hwang and Quigley, 2006; Kallberg et al, 2014) or the relationship between house prices and consumption (Case et al, 2005, 2012). Using a Bayesian framework, we identify to which public signals households over-respond. Our study is also different from the effect of overconfidence investigated in the US REITs market (Eichholtz and Yönder, 2015) or information asymmetry (Cline et al., 2014), where households can be regarded as noise traders in financial markets (De Long, et al. 1990). Household overconfidence is also different from sentiment that has attracted significant attention in the real estate literature, e.g., Gallimore and Gray (2002) and Brown and Matysiak (2000). Overconfidence is related to the precision of the expectation and is modelled as miscalibration as in our study whereas sentiment represents the personal feel or the state of the market that is driven by optimism or pessimism (Barone-Adesi et al., 2013).

The remainder of this paper is organized as follows. In Section II, we propose a novel method to test overconfidence bias in property returns when households misinterpret the accuracy of noisy public signals they use to predict house prices. In Section III, we estimate the effects of overconfidence in 12 UK regions. Finally, conclusions follow in Section IV. 


\section{The Effects of Household Overconfidence about Public Signals on House Prices}

\section{A. Bayesian Forecast with Noisy Signals}

We start with a simple linear pricing model for the return of property $i$ as follows:

$$
r_{i t+1}=\beta_{i 0}+\beta_{i 1} x_{1 t+1}+\cdots+\beta_{i K} x_{K t+1}+\varepsilon_{i t+1},
$$

where $x_{k t+1} \mathrm{~s}$ are explanatory variables for the property return at time $t+1$. The pricing model in equation (1) is not directly applicable for the prediction of property $i$ 's return for the households at time $t$, because the $t+1$ explanatory variables are not readily available to them.

However, various signals for the explanatory variables are available to households at time $t$. Examples of signals are economic growth, inflation, unemployment rate, or interest rate, which contain information about $x_{k t+1}$ s. As in Daniel et al. (1998), we assume that the signals are sum of $x_{k t+1}$ and noise as follows:

Assumption 1 The signals that are available to households at time t can be presented as sum of the variable at time $t+1$ and noise at time $t$ :

$$
S_{k t}=x_{k t+1}+\varepsilon_{k t}
$$

where the noise $\varepsilon_{k t} \sim N_{\text {i.i.d. }}\left(0, \sigma_{k}^{2}\right)$ is not correlated with $x_{k t+1}$.

Households at time $t$ can observe signals, but do not know how noisy the signals are: neither the detailed decomposition between $x_{k t+1}$ and $\varepsilon_{k t}$ nor the variance of $S_{k t}$ is known at time $t$. These will be known at time $t+1$ once $x_{k t+1}$ becomes available. 
Upon receiving $S_{k t}$ s, households form a posterior expectation of the return of residential property $i$ as follows: ${ }^{4}$

$$
E\left(r_{i t+1} \mid S_{k t} s\right)=E\left(r_{i t+1}\right)+\sum_{k=1}^{K} \gamma_{i k}\left(S_{k t}-E\left(S_{k t}\right)\right)
$$

where $E\left(r_{i t+1}\right)$ is the unconditional expected return of property $i$ and $\gamma_{i k}=\frac{\operatorname{Cov}\left(r_{i t+1}, S_{k t}\right)}{\operatorname{Var}\left(S_{k t}\right)}=$ $\frac{\operatorname{Cov}\left(r_{i t+1}, x_{k t+1}\right)}{\operatorname{Var}\left(x_{k t+1}\right)+\sigma_{k}^{2}}$. If $x_{k t+1}$ is known in advance at time $t$ (no noise), then $\gamma_{i k}$ in the posterior expectation becomes equivalent to $\beta_{i k}$ in equation (1): $\gamma_{i k}=\beta_{i k}=\frac{\operatorname{Cov}\left(r_{i t+1}, x_{k t+1}\right)}{\operatorname{Var}\left(x_{k t+1}\right)}$. It is clear that $\sigma_{k}^{2}$ reduces the weight on the signal because $\operatorname{Var}\left(S_{k t}\right)>\operatorname{Var}\left(x_{k t+1}\right)$. When signal becomes noisier ( $\sigma_{k}^{2}$ increases), $\gamma_{i k}$ decreases, indicating that households should reduce their weight on the signal.

\section{B. Bias in Posterior Expectation by Overconfidence}

The rational posterior expectation in equation (3) does not show how overconfident households respond to noisy signals. When households believe that the noisy signal they receive is more accurate than it really is, they underestimate (miscalibrate) the variance of noisy signal (Daniel et al., 1998). Let $\underline{\operatorname{Var}\left(S_{k t}\right)}$ denote the under-estimated variance of the noisy signal. Then, the difference between the true and biased variances (i.e., $\rho_{k} \equiv$ $\left.\operatorname{Var}\left(S_{k t}\right)-\operatorname{Var}\left(S_{k t}\right)\right)$ represents bias in the precision of the noisy signal, which is positive if households are overconfident (overprecision) in their signal. Households can be overconfident in some signals while they are not in others; thus, $\rho_{k t} \mathrm{~s}$ are not necessarily the

\footnotetext{
${ }^{4}$ If random variables $X$ and $Y$ follow a jointly normal distribution and their standard deviations and covariance are $\sigma_{X}^{2}, \sigma_{Y}^{2}$ and $\sigma_{X Y}$, the conditional expected value of $X$ given $Y$ is $E(X \mid Y)=$ $E(X)+\frac{\sigma_{X Y}}{\sigma_{Y}^{2}}\{Y-E(Y)\}$.
} 
same for all explanatory variables. Empirically, this possibility allows us to test about which signals households become more overconfident.

When households are overconfident in their signals, equation (3) can be represented as follows using $\rho_{k}$ :

$$
E^{b}\left(r_{i t+1} \mid S_{k t} s\right)=E\left(r_{i t+1}\right)+\sum_{k=1}^{K} \gamma_{i k}^{b_{a}}\left(S_{k t}-E\left(S_{k t}\right)\right)
$$

where $E^{b}(\cdot)$ represents the biased posterior expectation operator in the presence of overconfidence, and $\gamma_{i k}^{b_{a}}=\frac{\operatorname{Cov}\left(r_{i t+1}, S_{k t}\right)}{\operatorname{Var}\left(S_{k t}\right)-\rho_{i k}}$. Note that overconfidence appears as over-reaction to signals: i.e., the regression coefficients $\left(\gamma_{i k}^{b_{a}} \mathrm{~s}\right)$ in equation (4) are upwardly biased compared with those $\left(\gamma_{i k} \mathrm{~s}\right)$ in equation (3).

The mechanism through which overconfidence affects property returns is quite different from those of other cognitive biases in the literature. For example, herding that is frequently named as a source of mispricing and speculative bubbles is an alignment of thoughts or behaviours of individual households (Shiller, 2005). Regret theory suggests that households are drawn into the market when house prices increase because they want to avoid having regret about not participating in the market (Farlow, 2013). Households may be attracted by increase in nominal house prices (Brunnermeier and Julliard, 2008). ${ }^{5}$ These behavioural biases may explain boom-bust house prices, but do not explain biases in house prices due to the miscalibration of the precision of signals nor the signals that contribute to the biases.

The distortion in the relationship between the expected property return and the signal can be expressed as a ratio between the coefficients defined in equations (3) and (4) as follows:

\footnotetext{
${ }^{5}$ For a recent survey on behavioural real estate, see Salzman and Zwinkels (2017).
} 


$$
\frac{\gamma_{i k}^{b_{a}}}{\gamma_{i k}}=\frac{\frac{\operatorname{Cov}\left(r_{i t+1}, s_{k t}\right)}{\operatorname{Var}\left(s_{k t}\right)-\rho_{i k}}}{\frac{\operatorname{Cov}\left(r_{i t+1}, s_{k t}\right)}{\operatorname{Var}\left(s_{k t}\right)}}=\frac{\operatorname{Var}\left(s_{k t}\right)}{\operatorname{Var}\left(S_{k t}\right)-\rho_{i k}},
$$

from which the miscalibration can be obtained as $\rho_{i k}=\operatorname{Var}\left(S_{k t}\right)\left(1-\frac{\gamma_{i k}}{\gamma_{i k}^{b a}}\right)$. However, neither $\gamma_{i k}$ nor $\gamma_{i k}^{b_{a}}$ is known.

\section{Bias in Ex Post Property Return by Overconfidence}

When households buy or sell their properties following what they believe (i.e., according to the posterior expectation in equation (4)), the ex post property return would be significantly affected by their behavioural bias. ${ }^{6}$ In order to investigate household overconfidence using realised returns, we need the following assumption:

Assumption 2 Ex post returns fully reflect households' posterior expectation.

Under Assumption 2, the realised ex post property return $\left(r_{i t+1}^{b}\right)$ can be presented as the sum of the unbiased property return $\left(r_{i t+1}\right)$ and the bias $\left(\eta_{i t+1}\right)$ caused by overconfidence: $r_{i t+1}^{b}=r_{i t+1}+\eta_{i t+1}$. The testable ex post model for equation (4) is

$$
r_{i t+1}^{b}=\gamma_{i 0}+\sum_{k=1}^{K} \gamma_{i k}^{b_{p}} S_{k t}+e_{i t+1}
$$

where the regression coefficients are $\gamma_{i k}^{b_{p}}=\frac{\operatorname{Cov}\left(r_{i t+1}^{b}, s_{k t}\right)}{\operatorname{Var}\left(S_{k t}\right)}=\frac{\operatorname{Cov}\left(r_{i t+1}, x_{k t+1}\right)+\operatorname{Cov}\left(\eta_{i t+1}, \varepsilon_{k t}\right)}{\operatorname{Var}\left(S_{k t}\right)}$.

Unlike the ex ante coefficient $\gamma_{i k}^{b_{a}}$ in equation (4) where overconfidence is modelled by the

${ }^{6}$ As in most studies for irrational price movements in housing markets (Salzman and Zwinkels, 2017), households in the resident property market are not just price takers. When households buy or sell their houses according to their expectation, ex post realized residential property returns reflect their posterior expectation. 
unknown $\rho_{i k}$ in the denominator, the effects of overconfidence in equation (6) is now captured by $\operatorname{Cov}\left(\eta_{i t+1}, \varepsilon_{k t}\right)$ in the numerator of the coefficient $\gamma_{i k}^{b_{p}}$ because ex post $\operatorname{Var}\left(S_{k t}\right)$ is known (no bias) and the ex post return $r_{i t+1}^{b}$ includes the overconfidence bias $\eta_{i t+1}{ }^{7}$

Proposition 1 Under Assumptions 1 and 2, the miscalibration via overconfidence can be presented as

$$
\rho_{i k}=\operatorname{Var}\left(S_{k t}\right)\left(1-\frac{\delta_{i k}}{\delta_{i k}^{b}}\right)
$$

and the level of overconfidence can be represented as the ratio of $\delta_{i k}$ to $\delta_{i k}^{b}$ :

$$
\frac{\delta_{i k}}{\delta_{i k}^{b}}=\frac{\operatorname{Cov}\left(r_{i t+1}^{b}, x_{k t+1}\right)}{\operatorname{Cov}\left(r_{i t+1}^{b}, S_{k t}\right)}
$$

where $\delta_{i k}=\frac{\operatorname{Cov}\left(r_{i t+1}^{b}, x_{k t+1}\right)}{\operatorname{Var}\left(r_{i t+1}^{b}\right)}$ and $\delta_{i k}^{b}=\frac{\operatorname{Cov}\left(r_{i t+1}^{b}, S_{k t}\right)}{\operatorname{Var}\left(r_{i t+1}^{b}\right)}$.

Proof Under Assumptions 1 and 2, the two coefficients in equations (4) and (6) are the same. Thus the result can be obtained using $\gamma_{i k}^{b_{a}}=\frac{\operatorname{Cov}\left(r_{i t+1}, S_{k t}\right)}{\operatorname{Var}\left(S_{k t}\right)-\rho_{i k}}=\frac{\operatorname{Cov}\left(r_{i t+1}^{b}, s_{k t}\right)}{\operatorname{Var}\left(S_{k t}\right)}=\gamma_{i k}^{b_{p}}$ and $\frac{\gamma_{i k}}{\gamma_{i k}^{b a}}=\frac{\gamma_{i k}}{\gamma_{i k}}=\frac{\frac{\operatorname{Cov}\left(r_{i t+1}, s_{k t}\right)}{\operatorname{Var}\left(s_{k t}\right)}}{\frac{\operatorname{Cov}\left(r_{i t+1}^{b}, s_{k t}\right)}{\operatorname{Var}\left(s_{k t}\right)}}=\frac{\frac{\operatorname{Cov}\left(r_{i t+1}, s_{k t}\right)}{\operatorname{Var}\left(r_{i t+1}^{b}\right)}}{\frac{\operatorname{Cov}\left(r_{i t+1}^{b}, s_{k t}\right)}{\operatorname{Var}\left(r_{i t+1}^{b}\right)}}=\frac{\delta_{i k}}{\delta_{i k}^{b}}$, where the last equation can be obtained from $\operatorname{Cov}\left(r_{i t+1}, S_{k t}\right)=\operatorname{Cov}\left(r_{i t+1}, x_{k t+1}\right)=\operatorname{Cov}\left(r_{i t+1}^{b}, x_{k t+1}\right)$. Note that $\operatorname{Cov}\left(r_{i t+1}, S_{k t}\right)=$ $\operatorname{Cov}\left(r_{i t+1}, x_{k t+1}\right)$ because the noise in $S_{k t}$ is not correlated with $r_{i t+1}$ (Assumption 1) and

${ }^{7}$ Later in the empirical tests, we compare the ex post property return $r_{i t+1}^{b}$ with the biased posterior expectation $E^{b}\left(r_{i t+1} \mid S_{k t} s\right)$ as well as with the rational posterior expectation $E\left(r_{i t+1} \mid S_{k t} s\right)$. The empirical results show that $r_{i t+1}^{b}$ is indeed closer to $E^{b}\left(r_{i t+1} \mid S_{k t} s\right)$ than to $E\left(r_{i t+1} \mid S_{k t} s\right)$, indicating that overconfident households follow their biased posterior expectation for buying and selling their residential properties. 
$\operatorname{Cov}\left(r_{i t+1}, x_{k t+1}\right)=\operatorname{Cov}\left(r_{i t+1}+\eta_{i t+1}, x_{k t+1}\right)=\operatorname{Cov}\left(r_{i t+1}^{b}, x_{k t+1}\right)$ because the bias in the property return $\left(\eta_{i t+1}\right)$ is not created by $x_{k t+1}$ but by an underestimation (or overestimation) of $\operatorname{Var}\left(S_{k t}\right) . \quad Q E D$.

Under Assumption 2, the level of overconfidence $\frac{\gamma_{i k}}{\gamma_{i k}}$ from the ex post model in equation (6) is the same as $\frac{\delta_{i k}}{\delta_{i k}^{b}}$ in equation (7) that we can calculate using ex post realised data. ${ }^{8}$ Note that it is $\frac{\delta_{i k}}{\delta_{i k}^{b}}$ that measures overconfidence and the denominators of $\delta_{i k}$ and $\delta_{i k}^{b}$ are not important as far as they are the same. We use $\operatorname{Var}\left(r_{i t+1}^{b}\right)$ in the denominators of these two coefficients because they can be easily estimated with ex post data (see Proposition 2).

Finally, a positive value of $\rho_{i k}$ in equation (7) suggests $\operatorname{Cov}\left(r_{i t+1}^{b}, S_{k t}\right)>$ $\operatorname{Cov}\left(r_{i t+1}^{b}, x_{k t+1}\right)$ because households are overconfident about the noisy public signal: the property return at time $t+1\left(r_{i t+1}^{b}\right)$ responds to the noisy signal $\left(S_{k t}\right)$ more than to the true value of the explanatory variable $\left(x_{k t+1}\right)$. Therefore, in the presence of overconfidence, a positive signal would contribute to an upward bias in house prices, whereas a negative signal would lower the house prices below their fundamental values, increasing volatility of property returns.

We offer the following proposition to test household overconfidence:

Proposition 2 Under Assumptions 1 and 2, overconfidence in a noisy signal arises when

8 The ratio $\frac{\gamma_{i k}}{\gamma_{i k}}$ is not affected by cross-correlation between noisy signals $\left(S_{k t} \mathrm{~s}\right)$ because the effects of multicollinearity, which appear in the denominators of regression coefficients (both $\gamma_{i k}$ and $\gamma_{i k}^{b_{p}}$ ), are cancelled out when ratios are calculated. 
$\frac{\delta_{i k}}{\delta_{i k}^{b}}<1$ where $\delta_{i k}$ and $\delta_{i k}^{b}$ can be obtained from the regression coefficients in the following equations:

$$
\begin{gathered}
x_{k t+1}=\mu_{k}+\delta_{i k} r_{i t+1}^{b}+e_{k t+1}, \\
S_{k t}=\mu_{k}^{\prime}+\delta_{i k}^{b} r_{i t+1}^{b}+e_{k t+1}^{\prime},
\end{gathered}
$$

where $S_{k t}$ is the time t noisy signal for $x_{k t+1}$ that can be observed at time $t+1$, and $r_{i t+1}^{b}$ is the ex post return of property i. Alternatively, underconfidence arises when $\frac{\delta_{i k}}{\delta_{i k}^{b}}>1$. The test statistic for the null hypothesis $H_{0}: \delta_{i k}=\delta_{i k}^{b}$ can be obtained using the t-test:

$$
t=\frac{\hat{\delta}_{i k}-\hat{\delta}_{i k}^{b}}{\sqrt{s_{\hat{\delta}_{i k}}^{2}+s_{\hat{\delta}_{i k}^{b}}^{2}}} \sim T\left(n_{1}+n_{2}-4\right),
$$

where $s_{\widehat{\delta}_{i k}}$ and $s_{\widehat{\delta}_{i k}^{b}}$ are the standard errors of $\hat{\delta}_{i k}$ and $\hat{\delta}_{i k}^{b}$ respectively. QED.

Proof The regression coefficients $\delta_{i k}$ and $\delta_{i k}^{b}$ in equations (9a) and (9b) are $\delta_{i k}=$ $\frac{\operatorname{Cov}\left(x_{k t+1}, r_{i t+1}^{b}\right)}{\operatorname{Var}\left(r_{i t+1}^{b}\right)}$ and $\delta_{i k}^{b}=\frac{\operatorname{Cov}\left(s_{k t}, r_{i t+1}^{b}\right)}{\operatorname{Var}\left(r_{i t+1}^{b}\right)}$, respectively. The test statistic for the null hypothesis $\mathrm{H}_{0}: \frac{\delta_{i k}}{\delta_{i k}^{b}}=1$ is equivalent to $H_{0}: \delta_{i k}=\delta_{i k}^{b}$

Note that the regression equations (9a) and (9b) in Proposition 2 are not introduced to infer any causal relationship between the right-hand and left-hand variables: they are simply to estimate the ratio $\frac{\delta_{i k}}{\delta_{i k}^{b}}$ in Proposition 1.

\section{Noisy Public Signals}

Our measure of overconfidence can be applied to any signal $\left(S_{k t}\right)$ regardless of private or public signals. However, private signals are difficult to observe because they are by 
definition specific to households and are not known to others. ${ }^{9}$ Public signals, on the other hand, are known to general public, and thus overconfidence about public signals can be measured as explained above.

Instead of testing an arbitrarily large number of macroeconomic variables, we choose explanatory variables $\left(x_{k t+1} \mathrm{~s}\right)$ assuming that households are willing to change consumption over time and across different states of the world under the Epstein-Zin utility (Epstein and Zin, 1989, 1991). The result in the Appendix shows that property return can be explained by consumption and the wealth portfolio depending on the elasticity of intertemporal substitution and risk aversion. We further divide the wealth portfolio into stock and human capital because human capital forms a substantial part of the wealth portfolio in the economy (Mayers, 1972; Campbell, 1996; Jagannathan and Wang, 1996; Lettau and Ludvigson, 2001; Lustig and Van Nieuwerburgh 2008; Bansal et al., 2014; Caporale and Sousa, 2015).

We test two types of signals for these three core explanatory variables: stock return, changes in consumption and human capital. In both cases, lagged macroeconomic variables are used as noisy signals for these explanatory variables, because they are public and contain information about the future values of the explanatory variables. ${ }^{10}$ This setting resembles households' prediction of house prices in the sense that they use public information to update economic outlook to predict housing market.

\footnotetext{
${ }^{9}$ This is one reason why empirical studies on the effects of private information on asset pricing are rare. Most studies focus on theoretical consequences of overconfidence about private information (Odean, 1998; Daniel et al, 1998; Gervais and Odean, 2001).

${ }^{10}$ Most macroeconomic variables are autocorrelated and thus their past values can be used to predict their future.
} 
Note that our overconfidence measure $\frac{\delta_{i k}}{\delta_{i k}^{b}}=\frac{\operatorname{Cov}\left(r_{i t+1}^{b}, x_{\mathrm{k} t+1}\right)}{\operatorname{Cov}\left(r_{i t+1}^{b}, s_{\mathrm{k} t}\right)}$ is specific for the noisy signal defined as $S_{k t}=x_{k t+1}+\varepsilon_{k t}$. If signals are defined in a different way, then $\frac{\delta_{i k}}{\delta_{i k}^{b}}$ does not measure overconfidence as explained in the previous subsection. For example, if $S_{k t}=$ $\theta x_{k t+1}+\varepsilon_{k t}$ with a parameter $\theta \neq 1$, then $\frac{\delta_{i k}}{\delta_{i k}^{b}}=\frac{\operatorname{Cov}\left(r_{i t+1}^{b}, x_{k t+1}\right)}{\theta \operatorname{Cov}\left(x_{k t+1}, r_{i t+1}^{b}\right)+\operatorname{Cov}\left(\eta_{i t+1}, \varepsilon_{k t}\right)}$ depends on both $\theta$ and household overconfidence $\left(\operatorname{Cov}\left(\eta_{i t+1}, \varepsilon_{k t}\right)\right)$. Therefore, we need to construct $S_{k t}$ from lagged variables without changing the composition of $x_{k t+1}$ and $\varepsilon_{k t}$ that are included in the lagged variables.

The basic idea we use in this study is to scale lagged variables to construct signals in the form of $S_{k t}=x_{k t+1}+\varepsilon_{k t}$. For example, the lagged variable can be expressed as follows: $x_{k t}=\kappa x_{k t+1}+\epsilon_{k t}$, where $\kappa \neq 0$ if the lagged variable $x_{k t}$ has information about its future value. Then, we simply scale the lagged variable by $\frac{1}{\kappa}$ to obtain $\frac{x_{k t}}{\kappa}=x_{k t+1}+\frac{\epsilon_{k t}}{\kappa}$, and use $\frac{x_{k t}}{\kappa}$ instead of $x_{k t}$ as the noisy signal. In fact, $\frac{x_{k t}}{\kappa}$ and $x_{k t}$ are perfectly correlated, and thus, the scaling does not alter the content of information included in $x_{k t}$.

We first explain a simple case where lagged explanatory variables are used as nosy public signals. The noisy public signal can be calculated as follows:

$$
\begin{aligned}
& 1^{\text {st }} \text { step: } x_{k t}=\alpha_{k}+\beta_{k} x_{k t+1}+\epsilon_{i k t} \text { for } k=1, \ldots, K \\
& 2^{\text {nd }} \text { step: } S_{k t}=\frac{x_{k t}}{\beta_{i k}}-\frac{\alpha_{k}}{\beta_{k}}=x_{k t+1}+\varepsilon_{k t}, \text { where } \varepsilon_{k t}=\frac{\epsilon_{k t}}{\beta_{k}} \text { for } k=1, \ldots, K .
\end{aligned}
$$

The two steps are to decompose $x_{k t}$ into $x_{k t+1}$ and noise to obtain $S_{k t}$ under the assumption that the lagged variable $x_{k t}$ includes information about $x_{k t+1}$ : i.e., $\beta_{k} \neq 0$. Note that the regression in the first step is not to infer any causal relationship or explain $x_{k t}$ using $x_{k t+1}$. The variable $S_{k t}$ becomes noisier as $\beta_{k}$ is closer to zero, depending on informativeness of the lagged variable, but the two steps above does not change the 
composition of $x_{k t}$ in an arbitrary way. We use this case to test the robustness of the main results.

The second case that we use for our main results is that households have multiple lagged macroeconomic variables available to predict the three core variables. Let $f_{k j t} \mathrm{~s}$ be these macroeconomic variables for $x_{k t+1}$. Suppose that households have $J$ such variables. Then the combined noisy public signal for core variable $k$ can be represented as $S_{k t}=$ $\sum_{j=1}^{J} w_{k j} f_{k j t}$, where $w_{k j}$ is the weight on $f_{k j t}$ and $\sum_{j=1}^{J} w_{k j}=1$. We construct the noisy signals for the core explanatory variables using the following procedure:

$$
\begin{aligned}
& 1^{\text {st }} \text { step: } f_{k j t}=\alpha_{k j}+\beta_{k j} x_{k t+1}+\epsilon_{k j t} \text { for } j=1, \ldots, J \\
& 2^{\text {nd }} \text { step: } f_{k j t}^{*}=\frac{f_{k j t}}{\beta_{k j}}-\frac{\alpha_{k j}}{\beta_{k j}}=x_{k t+1}+\epsilon_{k j t}^{*} \text {, where } \epsilon_{k j t}^{*}=\frac{\epsilon_{k j t}}{\beta_{k j}} \text { for } j=1, \ldots, J . \\
& 3^{\text {rd }} \text { step: } x_{k t+1}=\mu+\sum_{j=1}^{J} \pi_{k j} f_{k j t}^{*}+\epsilon_{k t+1} \text { to obtain } w_{k j}^{*}=\frac{\pi_{k j}}{\sum_{j=1}^{J} \pi_{k j}} . \\
& 4^{\text {th }} \text { step: } S_{k t}=\sum_{j=1}^{J} w_{k j}^{*} f_{k j t}^{*}=x_{k t+1}+\sum_{j=1}^{J} w_{k j}^{*} \epsilon_{k j t}^{*} .
\end{aligned}
$$

The first two steps are the same as those in the first case except that lagged macroeconomic variables are used as signals for the core explanatory variables. The following two steps (steps 3 and 4) are required to combine $J$ macroeconomic variables for $S_{k t}$. We use the regression equation in the third step to calculate weights on $f_{k j t}^{*}$ s, because the regression coefficients $\left(\pi_{k j} \mathrm{~s}\right)$ give more weights on less noisy macroeconomic variables, which is consistent with our intuition. ${ }^{11}$ When a signal is constructed with various variables, the error term in the fourth step is the noise of the signal, i.e., $\varepsilon_{k t}=\sum_{k=1}^{K} w_{k j}^{*} \epsilon_{k j t}^{*}$, because

11 The least squares estimator $\pi_{k j}$ in the regression equation in Step $3 x_{k t+1}=\mu+$ $\sum_{k=1}^{K} \pi_{k j}\left(x_{k t+1}+\epsilon_{k j t}^{*}\right)+\epsilon_{k t+1}$ is $\pi_{k j}=\frac{\operatorname{Var}\left(x_{k t+1}\right)}{\operatorname{Var}\left(x_{k t+1}+\epsilon_{k j t}^{*}\right)}=\frac{1}{1+\frac{\operatorname{Var}\left(\epsilon_{k j t}^{*}\right)}{\operatorname{Var}\left(x_{k t+1}\right)}}$ which increases as
$\operatorname{var}\left(\epsilon_{k j t}^{*}\right)$ decreases. 
$\epsilon_{k j t}^{*} \mathrm{~s}$ do not have any information about $x_{k t+1}$. Thus, the noise $\varepsilon_{k t}$ is a part of the signal $\left(\sum_{k=1}^{K} w_{k j}^{*} \epsilon_{k j t}^{*}\right.$ from $\left.f_{k j t} \mathrm{~s}\right)$ used to predict the core variable $x_{\mathrm{x} t+1}$ but is not correlated with the core variable because $\operatorname{Cov}\left(x_{k t+1}, \epsilon_{k j t}^{*}\right)=\operatorname{Cov}\left(x_{k t+1}, \varepsilon_{k t}\right)=0$. It is important to note that the four steps do not change the content of information included in each lagged macroeconomic variable because we simply scale each macroeconomic variable and weight these scaled macroeconomic variables in an intuitive way. However, the choice of lagged macroeconomic variables and the weighting method may be arbitrary. We use the simple first case above to test the robustness of the main results.

\section{Empirical Tests}

\section{A. Data}

We measure household overconfidence across regions and over time using the Nationwide House Price Index for residential property returns from 1980 to $2018 .{ }^{12}$ The index provides quarterly returns for 12 UK regions - North East (NE), North West (NW), Yorkshire and the Humber (YH), East Midlands (EM), West Midlands (WM), East (E), London (L), South East (SE), South West (SW), Wales (W), Scotland (SL) and Northern Ireland (NI) - as well as a nationwide index (UK). ${ }^{13}$ Considering the frequencies in

12 The Nationwide House Price Index is a seasonally adjusted house price index calculated using Nationwide's lending data for residential properties at the post-survey approval stage. Nationwide is a large provider of household savings and mortgages in the UK and is the largest building society in the world.

13 These are the 12 first level Nomenclature of Territorial Units for Statistics regions (NUTS1 regions) that are used for statistical and administrative purposes. 
macroeconomic variables and the illiquidity in property markets, we use quarterly data in the empirical tests.

The details of the three core variables and lagged macroeconomic variables that are used to construct signals of these core variables are explained below. Consumption changes (CNSUMPTN_R) and stock returns (FTSE_ALL_R) are national while human capital changes are regional. ${ }^{14}$ The asterisks following the variable names on human capital changes (GDHI_*) and residential property returns $\left(\mathrm{R}_{-}{ }^{*}\right)$ represent names of regions.

\section{i. $\quad$ Consumption changes (CNSUMPTN_R)}

Previous studies have theoretically and empirically suggested various variables to predict consumption. Specifically, the permanent income hypothesis suggests that a higher expected future income raises current consumption (e.g., Hall and Mishkin, 1982; Engel and Rogers, 2009). The wealth effect posits that consumption increases along with UK house prices (Aron et al., 2006; Slacalek, 2009) or UK stock prices (Caporale and Sousa, 2015). Consumer confidence (Ludvigson, 2004) and GDP growth rates (De Giorgi and Gambetti, 2015) also affect consumption. Thus, we consider gross disposable household income change (GDHI_UK), UK residential property returns (R_UK), the FTSE All-Share index returns (FTSE_ALL_R), the consumer confidence index (CNFDNC), and GDP growth rate (GDP_R) to construct the signal for consumption changes. GDHI_UK and CNFDNC are

${ }^{14}$ There are significant restrictions in regional data for consumption and disposable household income, particularly for the 1980s. Due to data unavailability, we use national consumption data instead of regional consumption data for the entire sample period. For the gross disposable household income, we use national data until the end of 1989 and then use regional data from 1990 to the end of the sample period. 
from the Office for National Statistics and the OECD data, respectively. All other data are taken from Datastream.

\section{ii. $\quad$ Stock returns (FTSE_ALL_R)}

The literature finds that stock returns can be predicted by variables such as growth rate in industrial production (PRDCTN_A_R), unexpected change in inflation (CPI_R), credit spread (CRDT_SPRD), and term spread (TERM_SPRD) (Chen, Roll, and Ross, 1986). Other macroeconomic variables, such as the 10-year government bond yield (TB_10Y), unemployment rate (UMP), and change in sentiment index (SNTMNT_R), are also found to predict stock returns (e.g., Lettau and Ludvigson, 2001; Baker and Wurgler, 2006; Kelly and Pruitt, 2013).CPI_R and SNTMNT_R are from the Office for National Statistics and the OECD data, respectively. TB_10Y is from the Bank of England. All other data are taken from Datastream.

\section{iii. $\quad$ Regional human capital changes $\left(G D H I_{-}{ }^{*}\right)$}

As human capital is not directly observable, several methods have been proposed in the literature. In this study, we use gross disposable household income (GDHI) as a proxy for changes in household human capital for the following reasons. First, changes in human capital can be represented as a linear function of changes in per capita labour income if both labour income and human capital grow constantly and the growth rate of the former is higher 
than that of the latter (Jagannathan and Wang, 1996; Lustig and Nieuwerburgh, 2008). ${ }^{15}$

Second, homeownership is more likely to be a decision of households rather than individuals. Mortgage loans are in most cases borrowing against future household income (joint income of a household) rather than an individual in a household. Moreover, mortgage lenders consider the total net disposable income of income-earning individuals in a household, e.g., household income after income tax and national insurance. For robustness of our main results, we also use regional average weekly earnings per employee (AWE_*) (labour income) for human capital. The results in Table 6 show that our main story does not change.

Few studies have considered whether macroeconomic variables affect human capital although the literature regards it as a function of the state of the economy (Lustig and Nieuwerburgh, 2008; Bansal et al., 2014). Di Giovanni and Matsumoto (2011) explain the relationship between human capital changes and several macroeconomic variables, finding that human capital changes correlate with residential property returns, long-term bond yields, Treasury bill rates, and stock returns. We test these variables together with other macroeconomic variables, and choose regional residential property returns $\left(\mathrm{R}_{-}{ }^{*}\right)$, the 10 -year government bond yield (TB_10Y), FTSE index returns (FTSE_ALL_R), unemployment rate (UMP) and GDP growth rate (GDP_R) to construct the signal for human capital changes. GDHI_* and TB_10Y are from the Office for National Statistics and the Bank of England, respectively. All other data are taken from Datastream.

${ }_{15}$ Suppose that labour income grows at the rate of $g$ and human capital grows at the rate of $r$. When these two rates are constant over time and $r>g$, human capital is calculated as discounted future labour income: Human Capital $t=\frac{\text { Labour Income }_{t}}{r-g}$. Therefore, the change rate in the human capital is equivalent to the change in labour income: $\frac{\text { Human Capital } t-\text { Human Capital }_{t-1}}{\text { Human Capital }}=$ $\frac{\text { Labour }_{\text {Income }}-\text { Labour Income }_{t-1}}{\text { Labour Income }_{t-1}}$. 
Note that the macroeconomic variables we use for the prediction of the three core explanatory variables are not likely to include all the variables suggested in the literature. For example, changes in human capital may also be affected by the dynamics of demography that are closely associated with housing markets. The debt burden due to changes in higher education funding can delay homeownership (Andrews, 2010), and the growth of foreign populations may also affect regional housing markets (Sá, 2015; D’Albis et al., 2017; Sanchis-Guarner, 2017). The problem is that few of these data are available in quarterly frequency for our time series analysis. Because of this restriction, we focus on household overconfidence (over-response) in the selected variables rather than the best model for the prediction of house prices.

iv. $\quad$ Properties of variables ${ }^{16}$

The mean and standard deviation of quarterly UK property returns are $1.5 \%$ and $2.27 \%$, respectively. However, significant differences are observed across regions. The average return in London (L) appears to be the highest at $1.82 \%$ per quarter. Meanwhile, the average return in Northern Ireland (NI) region is $1.22 \%$, approximately two-thirds of that in London. London also shows the highest annual Sharpe ratio of 1.2 (annual average return of $7.3 \%$ divided by annual standard deviation of $6.1 \%$ ). Thus, residential properties in London have been the most attractive in terms of investment. By contrast, regions in north (NI, NE, YH) and Wales (W) show Sharpe ratios less than 0.9. The first-order autocorrelation coefficient of property returns in the entire United Kingdom is 0.79 , which means that UK property returns are persistent and predictable to some degree.

16 The detailed properties of the variables can be obtained from the authors upon request. 
Property returns are positively correlated with changes in consumption and other macroeconomic variables such as GDP growth, industrial production, consumer confidence, and sentiment (Baker and Wurgler, 2006; Attanasio et al, 2009). Changes in human capital are positively correlated with macroeconomic variables such as interest rates, inflation, GDP growth, and unemployment rate. Consumption growth is significantly correlated with macroeconomic variables such as GDP growth, industrial production, and consumer confidence. Stock returns, however, show less correlation with other macroeconomic variables.

\section{B. Properties of Noisy Signals}

Table 1 reports the regression results in the third step for the three core explanatory variables in Section II.D: $x_{k t+1}=\mu+\sum_{j=1}^{J} \pi_{k j} f_{k j t}^{*}+\epsilon_{k t+1}$. Panel A shows that it is difficult to forecast stock returns using lagged macroeconomic variables. Low R-square values for the prediction of stock returns are consistent with the results typically found in the finance literature. For example, R-square values are less than $1 \%$ for monthly stock returns (Kelly and Pruitt, 2013). Nonetheless, investors in financial markets are overconfident about signals even though they are not really informative (Daniel and Hirshleifer, 2015). In housing markets, we investigate if households also show overconfidence about signals of stock markets when they predict house prices. The results for changes in consumption in Panel B support the permanent income hypothesis because lagged household income that we use as a proxy of human capital explains future consumption. ${ }^{17}$ The main contributors $\left(w^{*}\right)$ to the

\footnotetext{
17 The results are consistent with Havranek and Sokolova (2020) who show that the permanent income hypothesis is consistent with data after correction for publication bias using a
} 
prediction of the core explanatory variables are unemployment rate and credit spread for stock returns, consumer confidence and property returns for consumption changes, and the Treasury Bond rate, GDP growth and unemployment rate for human capital changes.

[Table 1: see appendix]

Figure 1 shows the core explanatory variables $\left(x_{k t+1}\right)$ and their corresponding noisy signals $\left(S_{k t}=x_{k t+1}+\varepsilon_{k t}\right)$ constructed with the results in Table 1 for the United Kingdom. As expected, the noisy signals of the core explanatory variables are more volatile than the core explanatory variables: the quarterly standard deviations of stock market returns, consumption changes, and income changes are $7.5 \%, 0.8 \%$, and $1.3 \%$, respectively, whereas those of the noisy signals are $27.4 \%, 1.6 \%$, and $3.3 \%$, respectively. These differences in the volatilities of the noisy signals reflect the characteristics of the core variables. For example, consumption changes are more predictable than stock returns are: its signal is less noisier than the signal of stock returns is.

[Figure 1: see appendix]

\section{Household Overconfidence in the Noisy Public Signals}

To test overconfidence, we first estimate the coefficients on property returns for the core explanatory variables and their noisy signals (i.e., $\delta_{i k}$ and $\delta_{i k}^{b}$ ) in equations ( $9 a$ ) and (9b), respectively. Panel A in Table 2 reports that all three core variables have positive

comprehensive meta-analysis of 3000 tests of the permanent income hypothesis reported in 144 studies. 
relationships with property returns: the pooled regression coefficients $\hat{\delta}_{i k} \mathrm{~s}$ for stock returns, consumption changes, and human capital changes, are 0.26, 0.09, and 0.07, respectively, which increase to $0.72,0.27$, and 0.17 on the noisy public signals, respectively. ${ }^{18}$

The comparison between the two coefficients, $\delta_{i k}$ and $\delta_{i k}^{b}$, suggests that households respond to the noisy public signal $\left(S_{k t}\right)$ far more than to the true core variable because $\hat{\delta}_{i k}^{b}>$ $\hat{\delta}_{i k}$ is equivalent to $\operatorname{Cov}\left(r_{i t+1}^{b}, S_{k t}\right)>\operatorname{Cov}\left(r_{i t+1}^{b}, x_{k t+1}\right)$ for given $\operatorname{Var}\left(r_{i t+1}^{b}\right)$. The estimates of $\rho_{i k} \mathrm{~s}$ in Panel B are positive and delta ratios $\left(\delta_{i k} / \delta_{i k}^{b}\right)$ are also less than 1 in all cases. The R-squared values reported for the two regression equations (9a) and (9b) confirm that property returns are affected more by the lagged noisy signals than by the contemporaneous realizations for all three core variables.

[Table 2: see appendix]

In order to get the implication of the results in Table 2, we further investigate the explanatory power of contemporaneous core variables $\left(x_{k t+1} \mathrm{~s}\right)$ and noisy signals $\left(S_{k t} \mathrm{~s}\right)$. If households are rational and property returns are not affected by household overconfidence, the R-squared values using the realised core variables $\left(x_{k t+1} \mathrm{~s}\right)$ should be higher than those using lagged signals $\left(S_{k t} \mathrm{~s}\right)$ because the realised core variables do not include noise. Evidence that the R-squared value using lagged signals $\left(S_{k t} \mathrm{~s}\right)$ is higher than that using the realised core variables $\left(x_{k t+1} s\right)$ indicates that property returns are affected by household overconfidence about $S_{k t}$ s and thus biased.

18 The results of the pooled regression with 12 regions are marked "All 12 Regions" whereas those marked "UK" present estimates of a univariate regression with the aggregate data. The difference between the two lies in how each region is weighted: the pooled regression treats each region equally whereas the "UK" data are value-weighted. 
The two pooled regression results for the 12 regions are as follows:

$$
\begin{gathered}
r_{i t+1}^{b}=\underset{(0.003)}{0.005}+\underset{(0.027)}{0.022} x_{c t+1}+\underset{(0.265)}{1.204} x_{s t+1}+\underset{(0.033)}{0.046} x_{i h t+1}+e_{i t+1}^{b_{c}}\left(\mathrm{R}^{2}: 0.1\right) \\
r_{i t+1}^{b}=\underset{(0.001)}{0.008}+\underset{(0.006)}{0.007 S_{c t}}+\underset{(0.100)}{0.951} S_{s t}-\underset{(0.017)}{0.002 S_{h t}}+e_{i t+1}^{b_{p}}\left(\mathrm{R}^{2}: 0.25\right)
\end{gathered}
$$

where $c, s$, and $h$ represent consumption, stock, and human capital, respectively. The $\mathrm{R}$ squared value with the lagged noisy signals $\left(S_{k t} \mathrm{~s}\right)$ is much higher than that with $x_{k t+1} \mathrm{~s}$, confirming that property returns are significantly affected by the lagged noisy signals.

Property returns are significantly biased by the lagged signals of consumption changes. The null hypothesis $H_{0}: \delta_{i k}=\delta_{i k}^{b}$ is rejected at the $5 \%$ significant level for consumption changes regardless of regions. For the other two core variables, there are interesting regional variations although the statistical evidence is not as strong as that of consumption changes. For human capital changes in Panel B, the null hypothesis is rejected at the $10 \%$ level only in North West and Scotland where it is not rejected for stock returns. In fact, households in other northern regions such as NE, YH, EM, and WM also show similar patterns of overconfidence about the signals of human capital changes although it is not statistically significant. On the other hand, households in London and neighbouring regions such as East, South East, and South West where households do not show overconfidence about the noisy signals of human capital changes, show overconfidence about the signals of future stock returns.

The regional difference between stock returns and human capital changes raises an interesting question of why households respond differently to these signals. As both human capital and stocks constitute households' wealth portfolio, the results indicate difference in the wealth portfolio between these two groups of regions. A possible explanation from a psychological perspective is that the regional difference reflects a cognitive bias that people tend to believe that they are more informed about the familiar than the unfamiliar (Huberman, 
2001; Riff and Yagil, 2016). For example, households in London, who are better off and familiar with financial markets, believe that they are better informed than others and thus tend to weigh signals of financial markets too much. On the other hand, for households in northern regions who are less familiar with financial markets, and thus do not believe that the signals are informative. These cognitive limitations of households would increase the regional difference (Case et al, 2003).

\section{Effects of Overconfidence on Residential Property Returns}

The evidence of overconfidence in the signals of the three core explanatory variables shown in Table 2 does not directly show the extent to which property returns are affected by household overconfidence. Property returns may be affected by household overconfidence either negatively or positively, depending on the signs of the signals of the core explanatory variables. To investigate this issue, we first estimate how much the coefficients are biased by overconfidence using equations (5) and (6), and then compare property returns that overconfident and rational households expect.

Panel A of Table 3 reports the estimation results in equation (6): $r_{i t+1}^{b}=\gamma_{i 0}+$ $\sum_{k=1}^{K} \gamma_{i k}^{b_{p}} S_{k t}+e_{i t+1}$. The $t$-statistics of the coefficients on the noisy signal of consumption changes are well over three for all regions. However, the coefficients on the noisy signal of stock returns are significant in London and neighbouring regions whereas those on the noisy signal of human capital changes are positive and significant in northern regions. On average, these three noisy signals explain $30.8 \%$ of the realized property returns. The lowest predictive power is found in the Northern Ireland (10.4\%) and the highest in South East (44.2\%).

[Table: see appendix] 
The results in Panel B are the estimates of overconfidence-free coefficients $\left(\gamma_{i k} \mathrm{~s}\right)$, which we calculate $\gamma_{i k}=\gamma_{i k}^{b_{p}} \frac{\operatorname{Var}\left(S_{k t}\right)-\rho_{i k}}{\operatorname{Var}\left(S_{k t}\right)}$ from equation (5) assuming that $S_{k t} \mathrm{~s}$ are not correlated with each other. ${ }^{19}$ Most of the overconfidence-free coefficients are much smaller than those in Panel A. In other words, the coefficients in panel A are upward biased due to household overconfidence about the noisy public signals.

Using the overconfidence-free coefficients in Table 3, we finally calculate the return expected by rational households without overconfidence biases and the return expected by households who are overconfident in their noisy signals. Table 4 shows that the average return expected by UK households is higher than the return expected by rational households by $0.5 \%(=1.53 \%-1.03 \%)$ per quarter, and this difference is significant at the $1 \%$ level.

[Table: see appendix]

Household overconfidence contributes to the house price boom-busts. Figure 2 shows that households' expectations were upward-biased for more than 10 years, from 1997 to 2007, and remained so since the recovery from the financial crisis until the Brexit decision in 2016. The positive effects were particularly large in the 1980s, when households expected over 3\% more than the rational expectation for several quarters, indicating that household overconfidence about economic signals contributed to the bubble in the UK housing market in the 1980s. However, households expected negative property returns because of their overresponses to bad public signals in the early 1990s and a few years after the 2008 financial

19 As explained in Proposition 1, $\frac{\delta_{i k}}{\delta_{i k}^{b}}=\frac{\gamma_{i k}}{\gamma_{i k}}$ regardless of cross-correlation between the three variables. Thus we use $\rho_{i k}$ estimated with $\delta_{i k}$ and $\delta_{i k}^{b}$ to calculate $\gamma_{i k}$ in the multivariate regression. 
crisis. For example, the negative bias by overconfident households was over $-2 \%$ per quarter in the early 1990s and was over -3\% during the 2008 financial crisis. The results also show that the positive effects of household overconfidence in the 2010s disappeared and became even negative in many regions just after the Brexit referendum in 2016.

These patterns of overconfidence bias in the UK housing market can be compared with the effects of other cognitive biases. Adair et al. (2009) argue that the bubble in early to mid-2000s reflects inaccurate expectations among households that properties prices would increase indefinitely. The buoyant house prices increase even further by households who want to avoid having regret about not participating in the market (Farlow, 2013). Hott (2012) shows that household herd behaviour partly explain the huge increase in the UK house price from 1997 to 2007. However, many of these studies are based on surveys (e.g., Gallimore and Gray, 2002) or experiments (e.g., Seiler, Lane, and Harrison, 2014). Moreover, regional or temporal biases in the UK housing market by behavioural biases have not yet investigated thoroughly. ${ }^{20}$

[Figure 2: see appendix]

London shows an interesting pattern distinct from that of other regions in England. ${ }^{21}$ Over the 39 years from 1980 to 2018, households in London over-responded to the signals of

${ }^{20}$ Many behavioural studies that try to explain boom-bust price patterns in housing market have not been published partly due to the difficulties in estimating fundamental values of houses. In order to overcome this problem, we use a different approach which compares the responses of property returns to contemporaneous explanatory variables with those to the signals of these explanatory variables available to households.

${ }^{21}$ London housing market is indeed distinct from other UK markets. For example, our results may be affected by concentration of foreign investment in London than any other regions. 
consumption and stock returns, and their expected return was positively biased by $0.51 \%$ (= $1.82 \%-1.31 \%$ ) per quarter higher than what the rational households would have expected. However, most of the positive effect happened in the 1980s when stock returns were on average $6.2 \%$ per quarter (FTSE All Share Index return).

The positive effects of household overconfidence in London during the 2010s quickly disappeared after the second quarter of 2016 (the Brexit referendum): on average $-0.6 \%$ per quarter from the third quarter of 2016 to the end of 2018. Interestingly, Scotland also shows $0.7 \%$ per quarter during the same period. ${ }^{22}$ The results indicate that households in these two regions are far more sensitive to negative signals than those in the other regions.

Finally, the biased posterior expectations of overconfident households have significantly affected realized property returns. The average value of the correlation coefficient between the realized returns $\left(r_{i t+1}^{b}\right)$ and the overconfidence affected expected returns $\left(E^{b}\left(r_{i t+1} \mid S_{k t}\right)\right)$ is 0.56 . On the other hand, the average value of the correlation coefficients between the realized returns $\left(r_{i t+1}^{b}\right)$ and the overconfidence-bias-corrected returns $E\left(r_{i t+1} \mid S_{k t}\right)$ is 0.46 . Moreover, the average realized property returns $\left(r_{i t+1}^{b}\right)$ are similar to the posterior expectation affected by overconfidence (i.e., $\left.E^{b}\left(r_{i t+1} \mid S_{k t}\right)\right)$ : the average return difference between the two is close to zero.

\section{E. Robustness of the results}

We first test if our main results are affected by the specific construction method or macroeconomic variables that are used to construct noisy signals. For this purpose, we use lagged core variables as noisy signals of the core variables, and construct the noisy signals

${ }^{22}$ These differences in London and Scotland are significant at the $1 \%$ level. The detailed results of Table 6 can be obtained from the authors upon request. 
following the two steps in Section II.D for each of these core variables assuming that the best forecast can be obtained from its current value. The ratio of delta $\left(\delta_{i k} / \delta_{i k}^{b}\right)$ and the $t$ statistic for $\hat{\delta}_{i k}-\hat{\delta}_{i k}^{b}$ are calculated for each noisy signal in each region.

The results for the three core variables reported in Table 5 are similar to those in Table 4, despite the significant difference in the construction of noisy signals (one from combining various lagged macroeconomic variables following the four steps, and the other from its own lagged variable). The $t$ statistics reject the null hypothesis $H_{0}: \delta_{i k}=\delta_{i k}^{b}$ for consumption changes in most regions at the $10 \%$ significance level and for human capital changes in northern regions such as North East and West and Scotland. For stock returns, the null hypothesis is rejected in London and Scotland. Households in London have overconfidence about the noisy signals of financial markets whereas those far from the financial centre do not show overconfidence about signals of stock markets but over-respond to signals of future human capital changes.

[Table: see appendix]

We also use growth of regional average weekly earnings per employee (AWE) for human capital changes and report the results in Table 6 for the two core variablesconsumption and human capital changes. ${ }^{23}$ The results for consumption remain unchanged: the UK households still show overconfidence in the noisy signals of consumption. However, none of $\hat{\delta}_{i k} \mathrm{~s}$ and only a few $\hat{\delta}_{i k}^{b}$ s estimated with AWE are significant, indicating that AWE does not include information that can explain $t+1$ property returns. In contrast, nine $\hat{\delta}_{i k} \mathrm{~s}$ and eight $\hat{\delta}_{i k}^{b}$ s are significant when human capital is estimated with GDHI (Panel A of Table 2).

${ }^{23}$ Stock returns are not affected by a different proxy for human capital changes. 
These results suggest that household disposable income is a better proxy for human capital for the explanation of house prices than AWE.

[Table 6: see appendix]

\section{Implications and Conclusion}

Overconfidence is one of the most widely investigated behavioural biases in the literature, but the way household overconfidence affects house prices has not been investigated. Using a rational pricing model but allowing overconfidence during the information-updating process, we have investigated if households are overconfident in the UK housing market and have provided important new empirical findings.

Using residential property returns data for $12 \mathrm{UK}$ regions together with other macroeconomic variables, we find that UK households show overconfidence except for the periods when housing markets are in recession or during economic crises. They are overconfident in the noisy signals, in particular, for consumption growth. However, regional and time variations are observed in the overconfidence levels: households in northern regions tend to show overconfidence about signals of human capital changes whereas those in London are more likely to overrespond to signals of financial markets.

Our investigation of overconfidence in housing markets, however, have a few limits that require further studies. First, we focus on overprecision to signals as in Daniel et al. (1998) rather than other types of overconfidence such as overestimation or overplacement, and investigate how households respond to signals in Bayesian framework. Second, our results are specific to variables that we investigate in this study. In order to minimize arbitrariness in the choice of variables, we use the consumption-based asset pricing model to 
select three core variables that theoretically explain asset returns. However, these core variables suggested by the model may not be the only variables that household consider in reality. Although we show that our results are robust to an alternative way of forming noisy signals, other variables or methods need to be tested. We leave it for future study. 


\section{References}

Adair, A., J. Berry, M. Haran, G. Lloyd, and S. McGreal, 2009, The Global Financial Crisis: Impact on Property Markets in the UK and Ireland, Real Estate Initiative Research Team, University of Ulster.

Andrew, M., 2010, The changing route to owner occupation: The impact of student debt, Housing Studies 25(1): 39-62.

Aron, J., J. Muellbauer, and A. Murphyi, 2006, Housing Wealth and UK Consumption, Economic Outlook 30(4):11-20.

Attanasio, O.P., L. Blow, R. Hamilton, and A. Leicester, 2009, Booms and Busts: Consumption, House Prices and Expectations, Economica 76(301):20-50.

Baker M.P, J. Wurgler, 2006, Investor sentiment and the cross-section of stock returns. Journal of Finance 61(4):1645-1680.

Bansal, R., D. Kiku, I. Shaliastovich, and A. Yaron, 2014, Volatility, the Macroeconomy, and Asset Prices, Journal of Finance 69(6):2471-2511.

Barone-Adesi, G., L. Mancini and H. Shefrin, 2013, A Tale of Two Investors: Estimating Optimism and Overconfidence, 26th Australasian Finance and Banking Conference.

Brown, G.R., and G.A. Matysiak, 2000, Real Estate Investment, A Capital Market Approach, Pearson Education.

Brunnermeier, M. and C. Julliard, 2008, Money illusion and housing frenzies, The Review of Financial Studies 21(1):135-180.Campbell, J.Y. and J.F. Cocco, 2007, How do house prices affect consumption? Evidence from micro data, Journal of Monetary Economics 54:591-621.

Campbell, J.Y., 1996, Understanding Risk and Return, Journal of Political Economy 104: 298-345.

Caporale, G.M. and R.M. Sousa, 2015, Consumption, Wealth, Stock and Property returns: Evidence from Emerging Markets, Research in International Business and Finance forthcoming.

Case, K.E. and R.J. Shiller, 2003, Is There a Bubble in the Housing Market?, Brookings Papers on Economic Activity 34(2):299-362.

Case, K.E., J.M. Quigley, and R.J. Shiller, 2003, Home-buyers, Housing and the Macroeconomy, Paper presented at the Conference on Asset Prices and Monetary Policy. 
Case, K.E., J.M. Quigley, and R.J. Shiller, 2005, Comparing Wealth Effects: The Stock Market Versus The Housing Market, Advances in Macroeconomics 5(1):1-32.

Case, K.E., J.M. Quigley, and R.J. Shiller, 2012, Wealth Effects Revisited 1975-2012, Critical Finance Review 2012(2):101-128.

Clayton, J., 1998, Further Evidence on Real Estate Market Efficiency, Journal of Real Estate Research 15, 41-57.

Clayton, J., D. Geltner, and S.W. Hamilton, 2001, Smoothing in Commercial Property Valuation: Evidence from Individual Appraisals, Real Estate Economics 29(3):33760.

Cline, B., X. Fu, T. Springer, and T. Tang, 2014, Insider Trading in REITs: Evidence from Informed Stock Option Exercise Around Seasoned Equity Offerings, Journal of Real Estate Research 36(4), 511-540.

D'Albis, H., E. Boubtane, and D. Coulibaly, 2017, International Migration and Regional Housing Markets: Evidence from France, PSE Working Papers n²017-53. 2017.

Daniel, K. and D. Hirshleifer, 2015, Overconfident Investors, Predictable Returns, and Excessive Trading, Journal of Economic Perspectives 29(4):61-88.

Daniel, K., D. Hirshleifer, and A. Subrahmanyam, 1998, Investor psychology and security market under- and overreactions, Journal of Finance 53(6):1839-1885.

De Long, J. B., A. Shleifer, L. H. Summers, and R. J. Waldmann, 1990, Noise Trader Risk in Financial Markets, Journal of Political Economy 98(4):703-738.

De Giorgi, G. and L. Gambetti, 2015, Business cycle fluctuations and the distribution of consumption, Staff Reports 716, Federal Reserve Bank of New York.

Di Giovanni, J. and A. Matsumoto, 2011, The value of human capital wealth, Global COE Hi-Stat Discussion Paper Series 174, Institute of Economic Research, Hitotsubashi University.

Eichholtz, P. and E. Yönder, 2015, CEO Overconfidence, Corporate Investment Activity, and Performance: Evidence from REITs, Real Estate Economics 43(1), 139-162.

Elul, R., N.S. Souleles, S. Chomsisengphet, D. Glennon, and R. Hunt, 2010, What "Triggers" Mortgage Default? The American Economic Review 100(2): 490-494.

Engel, C. and J.H. Rogers, 2009, Expected Consumption Growth from Cross-Country Surveys: Implications for Assessing International Capital Markets, IMF Staff Papers, Palgrave Macmillan 56(3):543-573. 
Epstein, L. and S.E. Zin, 1989, Substitution, Risk Aversion, and the Temporal Behavior of Consumption and Asset Returns: a Theoretical Framework, Econometrica 57,937969.

Epstein, L. and S.E. Zin, 1991, Substitution, Risk Aversion, and the Temporal Behavior of Consumption and Asset Returns: an Empirical Analysis, Journal of Political Economy 99:263-286.

Farlow, A., 2013, Crash and Beyond. Oxford: Oxford University Press.Gallimore, P. and A. Gray, 2002, The Role of Investor Sentiment in Property Investment Decisions, Journal of Property Research 19(2):111-20.

Gallimore, P. and A. Gray, 2002, The role of investor sentiment in property investment decisions, Journal of Property Research 19(2):111-120.

Gervais, S. and T. Odean, 2001, Learning to be overconfident, Review of Financial Studies 14(1):1-27.

Goetzmann, W.N., 1993, The Single Family Home in the Investment Portfolio, The Journal of Real Estate Finance and Economics 6(3):201-22.

Hall, R.E. and F.S. Mishkin, 1982, The Sensitivity of Consumption to Transitory Income Estimates from Panel Data on Households, Econometrica 50:461-481.

Havranek, T. and A. Sokolova, 2020, Do Consumers Really Follow a Rule of Thumb? Three Thousand Estimates from 144 Studies Say 'Probably Not', Review of Economic Dynamics 35:97-122.

Helbling, T. and M.E. Terrones, 2003, Real and Financial Effects of Bursting Asset Price Bubbles, IMF World Economic Outlook April 2003:61-94.

Hott, C., 2012, The Influence of Herding Behavior on House Prices, Journal of European Real Estate Research 5(3):177-198.

Huberman, J., 2001, Familiarity Breeds of Investment, Review of Financial Studies 14, 659680.

Hwang, M. and J.M. Quigley, 2006, Economic Fundamentals in Local Housing Markets:

Evidence from U.S. Metropolitan Regions, Journal of Regioanl Science 46(3):425453.

Iacoviello, M., 2005, House Prices, Borrowing Constraints, and Monetary Policy in the Business Cycle, American Economic Review 95(3):739-764.

Jagannathan, R. and Z. Wang, 1996, The Conditional CAPM and the Cross-Section of Expected Returns, Journal of Finance 51(1):3-53. 
Kahneman, D. (2011), Thinking fast and slow, Farrar, Straus and Giroux, New York.

Kallberg, J.C., C.H. Liu, and P. Pasquariello, 2014, On the price comovement of U.S. residential real estate markets, Real Estate Economics 42(1):71-108.

Kelly, R., F. McCann, C. O’Toole, 2018, Credit conditions, macro-prudential policy and house prices, Journal of Housing Economics 41:153-167.

Kelly, B. and S. Pruitt, 2013, Market Expectations in the Cross-Section of Present Values, Journal of Finance 68(5):1721-1756.

Ludvigson, S.C., 2004, Consumer Confidence and Consumer Spending, Journal of Economic Perspectives 18(2): 29-50.

Lettau, M. and S. Ludvigson, 2001, Consumption, Aggregate Wealth and Expected Stock Returns, Journal of Finance 56:815-849.

Lustig, H. and S. Van Nieuwerburgh, 2008, The Returns on Human Capital: Good News on Wall Street is Bad News on Main Street, Review of Financial Studies 21(5):20972137.

Mayers, D., 1972, Nonmarketable Assets and Capital Market Equilibrium under Uncertainty. In: Jensen, M.C., Ed., Studies in the Theory of Capital Markets, 223-248.

Mian, A. and A. Sufi, 2009, The Consequences of Mortgage Credit Expansion: Evidence from the U.S. Mortgage Default Crisis, The Quarterly Journal of Economics 124(4):1449-1496,

Moore, D.A. and P.J. Healy, 2008, The Trouble with Overconfidence, Psychological Review 115(2):502-517.

Odean, T., 1998, Are investors reluctant to realize their losses?, Journal of Finance 53(5):1775-1798.

Okunev, J., P, Wilson, and R. Zurbruegg, 2000, The causal relationship between real estate and stock markets, Journal of Real Estate Finance and Economics 21(3), 251-261.

Riff, S. and Y. Yagil, 2016, Behavioral Factors Affecting the Home Bias Phenomenon:

Experimental Tests, Journal of Behavioral Finance 17, 267-279.

Sá, F. (2015), "Immigration and House Prices in the UK", The Economic Journal, Vol. 125, Issue 587: 1393-1424 (ABS 4)

Salzman, D. and R.C.J. Zwinkels, 2017, Behavioral Real Estate, Journal of Real Estate Literature 25: 77-106.

Sanchis-Guarner, R., 2017, Decomposing the Impact of Immigration on House Prices, SERC Discussion Paper 223. 
Seiler, M., M. Lane, and D. Harrison, 2014, Mimetic Herding Behavior and the Decision to Strategically Default, Journal of Real Estate Finance and Economics 49(4).

Shiller, R.J., 2005, Irrational Exuberance, Princeton University Press.

Shiller, R.J., 2006, Long-Term Perspectives on the Current Boom in Home Prices, The Economists' Voice 3(4):1-11.

Slacalek, J., 2009, What Drives Personal Consumption? The Role of Housing and Financial Wealth, ECB Working Paper No.1117. 


\section{Appendix}

Epstein and Zin $(1989,1991)$ add the elasticity of intertemporal substitution in consumption to the conventional power utility and propose a utility function for a representative household, $u_{t}$;

$$
u_{t}=\left[(1-\beta) C_{t}^{(1-\gamma) / \theta}+\beta\left(E_{t}\left(u_{t+1}^{1-\gamma}\right)\right)^{1 / \theta}\right]^{\theta /(1-\gamma)}
$$

where $\theta=(1-\gamma) /\left(1-\frac{1}{\psi}\right), \gamma$ is risk aversion, $\psi$ is the elasticity of intertemporal substitution, $\beta$ is time preference, and $C_{t}$ is consumption at time $t$. In this Epstein-Zin utility, the sensitivity of consumption change with respect to the interest rate is captured by the elasticity of intertemporal substitution $\psi$. Suppose that a household consumes from its wealth $\left(W_{t}\right)$ and invests the remainder in a wealth portfolio $p$. Thus, $W_{t+1}=(1+$ $\left.x_{p t+1}\right)\left(W_{t}-C_{t}\right)$, where $x_{p t+1}$ is the arithmetic return of the aggregate wealth portfolio at time $t+1$. Then, using dynamic programming arguments, Epstein and Zin show that the Euler equation for the above utility becomes

$$
E_{t}\left[M_{t+1}\left(1+r_{i t+1}\right)\right]=1
$$

in equilibrium, where the entire perishable output is consumed and the bond market is cleared. Here, the stochastic discount factor $M_{t+1}$ is defined as $M_{t+1} \equiv$ $\left\{\beta\left(\frac{C_{t+1}}{C_{t}}\right)^{-1 / \psi}\right\}^{\theta}\left\{\frac{1}{1+x_{p t+1}}\right\}^{1-\theta}$, and $r_{i t+1}$ is the arithmetic return of an asset. In our case, the asset is residential property $i$.

When the portfolio return and consumption follow a joint log-normal distribution, ${ }^{\mathrm{A} 1}$ taking a natural $\log$ on both sides of the above equation yields

$$
\ln E_{t}\left[M_{t+1}\left(1+r_{i t+1}\right)\right]=E_{t}\left[m_{t+1}+R_{i t+1}\right]+\frac{1}{2} \operatorname{Var}_{t}\left[m_{t+1}+R_{i t+1}\right]=0,
$$

where the $\log$ stochastic discount factor is $m_{t+1}=\ln M_{t+1}=\theta \ln \beta-\frac{\theta}{\psi} X_{c t+1}+$ $(\theta-1) X_{p t+1}, X_{p t+1}$ and $X_{i t+1}$ are log-returns of the wealth portfolio and residential property $i$, respectively, i.e., $X_{p t+1}=\ln \left(1+x_{p t+1}\right)$ and $X_{i t+1}=\ln \left(1+x_{i t+1}\right)$, and $X_{c t+1}$ is the $\log$ consumption change, i.e., $X_{c t+1} \equiv \ln \frac{C_{t+1}}{C_{t}}=\ln \left(1+x_{c t+1}\right)$. Rearranging the equation above, the expected portfolio return can be written as

${ }^{\text {A1 }}$ When a random variable $X$ is conditionally lognormally distributed, its expected return is

$$
\log E_{t}[X]=E_{t}[\log X]+\frac{1}{2} \operatorname{Var}_{t}[\log X] \text { (Campbell, Lo, and Mackinlay, 1997, pp. 306-307). }
$$




$$
E_{t}\left(R_{i t+1}\right)=-E_{t}\left(m_{t+1}\right)-\frac{1}{2}\left[\operatorname{Var}_{t}\left(m_{t+1}\right)+\operatorname{Var}_{t}\left(R_{i t+1}\right)+2 \operatorname{Cov}_{t}\left(m_{t+1}, R_{i t+1}\right)\right] .
$$

Because equation (A4) also holds for the risk-free asset, we have

$$
R_{f t+1}=-E_{t}\left(m_{t+1}\right)-\frac{1}{2} \operatorname{Var}_{t}\left(m_{t+1}\right)
$$

Combining the two equations yields the consumption-based model with the Epstein-Zin utility:

$$
E_{t}\left(R_{i t+1}-R_{f t+1}\right)+\frac{\sigma_{i t}^{2}}{2}=\theta \frac{\operatorname{Cov}_{t}\left(R_{i t+1}, X_{c t+1}\right)}{\psi}+(1-\theta) \operatorname{Cov}_{t}\left(R_{i t+1}, X_{p t+1}\right),
$$

where $\sigma_{i t}^{2}=\operatorname{Var}_{t}\left(R_{i t+1}\right)$. When $\theta=0$, the model is equivalent to the conventional capital asset pricing model (CAPM) of Sharpe (1964), Lintner (1965), and Mossin (1966):

$$
E_{t}\left(R_{i t+1}-R_{f t+1}\right)+\frac{\sigma_{i t}^{2}}{2}=\gamma \operatorname{Cov}_{t}\left(R_{i t+1}, X_{p t+1}\right) .
$$

Meanwhile, when $\gamma=\frac{1}{\psi}$ or $\theta=1$, the model becomes the consumption-based CAPM of Breeden (1979) and Hansen and Singleton (1983); thus, $E_{t}\left(R_{i t+1}-R_{f t+1}\right)+\frac{\sigma_{i t}^{2}}{2}=$ $\gamma \operatorname{Cov}_{t}\left(R_{i t+1}, X_{c t+1}\right)$. In general, the consumption-based model with the Epstein-Zin utility suggests that the expected excess return of residential property $i$ is explained by both the elasticity of intertemporal substitution $(\psi$ via $\theta)$ and risk aversion $(\gamma)$. The relative ratio of the two coefficients on the co-variances in equation (A6), i.e., $\frac{\theta / \psi}{1-\theta}=\frac{1-\gamma}{\psi \gamma-1}$, suggests that, as the elasticity of intertemporal substitution increases ( $\psi$ increases), the expected excess return is affected more by the aggregate wealth portfolio than by consumption growth.

Wealth portfolio $p$ consists of equities as well as human capital (Mayers, 1972; Jagannathan and Wang, 1996). Human capital would be particularly significant in pricing residential properties because major funding for residential properties, i.e., mortgages, is in fact backed by human capital. Therefore, following the literature (Campbell, 1996; Jagannathan and Wang, 1996; Lettau and Ludvigson, 2001; Lustig and Van Nieuwerburgh 2008; Bansal, Kiku, Shaliastovich, and Yaron, 2014; Caporale and Sousa, 2015), we further decompose the wealth portfolio into stocks and human capital, weighted $w_{s t}$ and $1-w_{s t}$, respectively.

Therefore, for a household who has Epstein-Zin utility, the expected return of property $i$ is presented with betas:

$$
E_{t}\left(r_{i t+1}-r_{f t+1}\right)=\beta_{i c t} \lambda_{c t}+\beta_{i s t} \lambda_{s t}+\beta_{i h t} \lambda_{h t},
$$


where $\beta_{i c t}=\frac{\operatorname{Cov}_{t}\left(r_{i t+1}, x_{c t+1}\right)}{\operatorname{Var}_{t}\left(x_{c t+1}\right)}, \beta_{i s t}=\frac{\operatorname{Cov}_{t}\left(r_{i t+1}, x_{s t+1}\right)}{\operatorname{Var}_{t}\left(x_{s t+1}\right)}, \beta_{i h t}=\frac{\operatorname{Cov}_{t}\left(r_{i t+1}, x_{h t+1}\right)}{\operatorname{Var}_{t}\left(x_{h t+1}\right)}$ and $\lambda_{c t}=$ $\frac{\theta}{\psi} \operatorname{Var}_{t}\left(x_{c t+1}\right), \lambda_{s t}=(1-\theta) w_{s t} \operatorname{Var}_{t}\left(x_{s t+1}\right), \lambda_{p t}=(1-\theta)\left(1-w_{s t}\right) \operatorname{Var}_{t}\left(x_{h t+1}\right)$, and $x_{c t+1}, x_{s t+1}$ and $x_{h t+1}$ represent change in consumption, the stock return, and change in human capital, respectively.

Because $\beta_{i c t}, \beta_{i s t}$, and $\beta_{i h t}$ are the coefficients from regressing the excess return of residential property $i$ on $x_{c t+1}, x_{s t+1}$, and $x_{h t+1}$, respectively, a testable time series model for the cross-sectional pricing model in equation (A7) can be presented as follows:

$$
r_{i t+1}-r_{f t+1}=\beta_{i 0 t}+\beta_{i c t} x_{c t+1}+\beta_{i s t} x_{s t+1}+\beta_{i h t} x_{h t+1}+\varepsilon_{i t+1},
$$

It becomes clear that $\beta_{i c t}, \beta_{i s t}$, and $\beta_{i h t}$, the three components in the model with the Epstein-Zin utility, appear as regression coefficients in the time series model in equation (A8). The relationship between (A7) and (A8) is analogous to that between the CAPM and the market model. In this study, the three variables $x_{c t+1}, x_{s t+1}$, and $x_{h t+1}$ are referred to as the core explanatory variables to differentiate them from other macroeconomic variables used to predict them. 
Table 1. Regression results for the signals of the three core explanatory variables

This table presents the regression results of the three core variables $\left(x_{k t+1}\right)$ - FTSE_ALL_R (FTSE All-share index returns), CNSUMPTN_R (consumption changes), and GDHI_* (regional gross disposable household income changes) — on the scaled macroeconomic variables $f_{k j t}^{*} \mathrm{~s}$ of the second step of the construction of noisy signals:

$$
x_{k t+1}=\mu+\sum_{j=1}^{J} \pi_{k j} f_{k j t}^{*}+\epsilon_{k t+1}
$$

where $x_{k t+1}$ represents the core explanatory variable, and $f_{k j t}^{*} \mathrm{~s}$ are scaled macroeconomic variables $\left(f_{k j t}^{*}=\right.$ $\frac{f_{k j t}}{\beta_{k j}}-\frac{\alpha_{k j}}{\beta_{k j}}$ from $\left.f_{k j t}=\alpha_{k j}+\beta_{k j} x_{k t+1}+\epsilon_{k j t}\right) . w_{k j}^{*}$ s are weights calculated with the regression coefficients $\left(w_{k j}^{*}=\frac{\pi_{k j}}{\sum_{j=1}^{J} \pi_{k j}}\right) .(+1)$ represents a one-quarter ahead variable. Bold numbers show significance at the $10 \%$ level.

A. Regression of FTSE index returns (FTSE_ALL_R(+1))

\begin{tabular}{cccc} 
Explanatory variables & Coefficients & Std. Error & $w_{k j}^{*}$ \\
\hline C & $\mathbf{0 . 0 2 9}$ & $(0.006)$ & \\
CPI_R & -0.002 & $(0.004)$ & -0.026 \\
PRDCTN_A_R & 0.000 & $(0.001)$ & -0.003 \\
SNTMNT_R & 0.000 & $(0.001)$ & -0.001 \\
TB_10Y & -0.002 & $(0.024)$ & -0.023 \\
TERM_SPRD & 0.000 & $(0.000)$ & 0.002 \\
CRDT_SPRD & 0.013 & $(0.011)$ & 0.172 \\
UMP & $\mathbf{0 . 0 7 1}$ & $(0.033)$ & 0.939 \\
CNFDNC & -0.004 & $(0.005)$ & -0.050 \\
FTSE_ALL_R & -0.001 & $(0.003)$ & -0.009 \\
\hline Adjusted R-squared & $1.81 \%$ & & \\
Durbin-Watson stat & 2.012 & & \\
\hline
\end{tabular}

B. Regression of consumption changes (CNSUMPTN_R(+1))

\begin{tabular}{cccc} 
Explanatory variables & Coefficients & Std. Error & $w_{k j}^{*}$ \\
\hline C & $\mathbf{0 . 0 0 5}$ & $(0.001)$ & \\
GDHI_UK & $\mathbf{0 . 0 2 1}$ & $(0.011)$ & 0.087 \\
R_UK & $\mathbf{0 . 0 8 2}$ & $(0.037)$ & 0.332 \\
FTSE_ALL_R & 0.006 & $(0.010)$ & 0.023 \\
CNFDNC & $\mathbf{0 . 1 3 3}$ & $(0.047)$ & 0.540 \\
GDP_R & 0.004 & $(0.017)$ & 0.018 \\
\hline Adjusted R-squared & $22.07 \%$ & & \\
Durbin-Watson stat & 1.800 & & \\
\hline
\end{tabular}

C. Pooled regression of regional gross disposable household income changes (GDHI_*(+1))

\begin{tabular}{cccc} 
Explanatory variables & Coefficients & Std. Error & $w_{k j}^{*}$ \\
\hline C & $\mathbf{0 . 0 1 0}$ & $(0.001)$ & \\
FTSE_ALL_M_R & 0.003 & $(0.006)$ & 0.015 \\
R_* & $\mathbf{0 . 0 1 1}$ & $(0.004)$ & 0.053 \\
TB_10Y & $\mathbf{0 . 2 1 0}$ & $(0.030)$ & 0.999 \\
GDP_R & $\mathbf{0 . 0 2 7}$ & $(0.022)$ & 0.127 \\
UMP & $\mathbf{- 0 . 0 2 6}$ & $(0.015)$ & -0.126 \\
GDHI_* & $\mathbf{- 0 . 0 1 4}$ & $(0.007)$ & -0.068 \\
\hline Adjusted R-squared & $20.72 \%$ & & \\
Durbin-Watson stat & 2.071 & & \\
\hline
\end{tabular}


Table 2. Overconfidence in the core explanatory variables

Panel A shows the regression results of the noiseless signals and noisy signals on the property returns in equations (9a) and (9b):

$$
\begin{gathered}
x_{k t+1}=\mu_{k}+\delta_{i k} r_{i t+1}^{b}+e_{k t+1}, \\
S_{k t}=\mu_{k}^{\prime}+\delta_{i k}^{b} r_{i t+1}^{b}+e_{k t+1}^{\prime},
\end{gathered}
$$

where $S_{k t}, x_{k t+1}$, and $r_{i t+1}^{b}$ are the noisy signal, the realized signal, and the realized property return, respectively. In Panel A, we use a common constant because fixed cross-section effects appear not to be significant in the pooled regressions. Panel B reports the ratios of deltas $\left(\delta_{i k} / \delta_{i k}^{b}\right)$, the $t$ statistics for $\hat{\delta}_{i k}-\hat{\delta}_{i k}^{b}$, and overconfidence biases $\left(\rho_{i k}\right)$ in the UK as well as twelve UK regions: North East (NE), North West (NW), Yorkshire and the Humber (YH), East Midlands (EM), West Midlands (WM), East (E), London (L), South East (SE), South West (SW), Wales (W), Scotland (SL) and Northern Ireland (NI). All 12 regions, A, B, and C report the results of pooled regressions. Bold numbers show significance at the $10 \%$ level. \# on overconfidence represents that the numbers are multiplied by 100 to increase visibility.

A. Results of regression of the core explanatory variables and their noisy signals on property returns

\begin{tabular}{ccccc} 
& \multicolumn{4}{c}{ Stock market returns } \\
\cline { 2 - 5 } UK & \multicolumn{3}{c}{$\hat{\delta}_{i k}$} & \multicolumn{3}{c}{$\hat{\delta}_{i k}^{b}$} \\
\cline { 2 - 5 } NE & $\mathbf{0 . 4 3 8}$ & $(0.264)$ & 1.561 & $(0.964)$ \\
NW & 0.076 & $(0.181)$ & 0.045 & $(0.663)$ \\
YH & $\mathbf{0 . 5 6 3}$ & $(0.221)$ & 0.409 & $(0.826)$ \\
EM & 0.271 & $(0.186)$ & 0.474 & $(0.681)$ \\
WM & 0.086 & $(0.203)$ & 0.948 & $(0.742)$ \\
E & 0.135 & $(0.225)$ & 1.151 & $(0.815)$ \\
L & 0.219 & $(0.187)$ & $\mathbf{1 . 4 4 4}$ & $(0.679)$ \\
SE & 0.325 & $(0.198)$ & $\mathbf{1 . 8 5 1}$ & $(0.712)$ \\
SW & 0.295 & $(0.211)$ & $\mathbf{1 . 9 9 1}$ & $(0.759)$ \\
W & 0.194 & $(0.219)$ & $\mathbf{1 . 5 6 1}$ & $(0.789)$ \\
NI & 0.263 & $(0.186)$ & 0.347 & $(0.683)$ \\
\hline Average Adj. R & 0.410 & $(0.263)$ & 0.151 & $(0.966)$ \\
\hline All 12 Regions & $\mathbf{0 . 3 4 1}$ & $(0.155)$ & -0.673 & $(0.573)$ \\
\hline A (L, SE, SW, E) & 0.014 & & 0.015 & \\
\hline B (NE, NW, YH, WM, WM) & 0.257 & $(0.187)$ & 0.718 & $(0.466)$ \\
\hline C (W, SL, NI) & 0.258 & $(0.228)$ & $\mathbf{1 . 6 9 9}$ & $(0.624)$ \\
\hline Difference between A and B (t-stat) & 0.211 & $(0.213)$ & 0.559 & $(0.527)$ \\
\hline Difference between A and C (t-stat) & 0.326 & $(0.163)$ & -0.181 & $(0.425)$ \\
\hline
\end{tabular}

\begin{tabular}{llll}
\multicolumn{4}{c}{ Consumption changes } \\
\hline \multicolumn{3}{c}{$\hat{\delta}_{i k}$} & \multicolumn{2}{c}{$\hat{\delta}_{i k}^{b}$} \\
\hline $\mathbf{0 . 1 6 6}$ & $(0.024)$ & $\mathbf{0 . 4 9 5}$ & $(0.039)$ \\
$\mathbf{0 . 0 4 6}$ & $(0.019)$ & $\mathbf{0 . 1 9 8}$ & $(0.035)$ \\
$\mathbf{0 . 0 9 8}$ & $(0.022)$ & $\mathbf{0 . 3 3 2}$ & $(0.040)$ \\
$\mathbf{0 . 0 6 3}$ & $(0.019)$ & $\mathbf{0 . 2 6 8}$ & $(0.033)$ \\
$\mathbf{0 . 1 1 0}$ & $(0.019)$ & $\mathbf{0 . 3 2 9}$ & $(0.034)$ \\
$\mathbf{0 . 1 1 7}$ & $(0.022)$ & $\mathbf{0 . 3 6 0}$ & $(0.037)$ \\
$\mathbf{0 . 1 1 3}$ & $(0.017)$ & $\mathbf{0 . 2 6 1}$ & $(0.034)$ \\
$\mathbf{0 . 1 0 7}$ & $(0.019)$ & $\mathbf{0 . 2 9 2}$ & $(0.035)$ \\
$\mathbf{0 . 1 3 9}$ & $(0.019)$ & $\mathbf{0 . 3 5 3}$ & $(0.035)$ \\
$\mathbf{0 . 1 3 9}$ & $(0.019)$ & $\mathbf{0 . 3 4 2}$ & $(0.037)$ \\
$\mathbf{0 . 0 6 0}$ & $(0.019)$ & $\mathbf{0 . 2 4 1}$ & $(0.034)$ \\
$\mathbf{0 . 0 7 2}$ & $(0.027)$ & $\mathbf{0 . 2 9 3}$ & $(0.051)$ \\
$\mathbf{0 . 0 4 8}$ & $(0.016)$ & $\mathbf{0 . 1 3 3}$ & $(0.031)$ \\
\hline 0.139 & & 0.302 & \\
\hline $\mathbf{0 . 0 8 8}$ & $(0.014)$ & $\mathbf{0 . 2 6 8}$ & $(0.027)$ \\
\hline $\mathbf{0 . 1 2 2}$ & $(0.015)$ & $\mathbf{0 . 3 1 3}$ & $(0.032)$ \\
\hline $\mathbf{0 . 0 8 2}$ & $(0.016)$ & $\mathbf{0 . 2 9 2}$ & $(0.028)$ \\
\hline $\mathbf{0 . 0 5 6}$ & $(0.014)$ & $\mathbf{0 . 2 0 1}$ & $(0.031)$ \\
\hline $\mathbf{- 1 . 8 3 6}$ & & -0.507 & \\
\hline $\mathbf{- 3 . 2 3 2}$ & & $\mathbf{- 2 . 5 3 1}$ & \\
\hline & & & \\
\hline
\end{tabular}

\begin{tabular}{cccc}
\multicolumn{4}{c}{ Household income changes } \\
\hline \multicolumn{3}{c}{$\hat{\delta}_{i k}$} & \multicolumn{2}{c}{$\hat{\delta}_{i k}^{b}$} \\
\hline 0.008 & $(0.046)$ & $\mathbf{0 . 2 5 4}$ & $(0.116)$ \\
$\mathbf{0 . 0 7 9}$ & $(0.028)$ & $\mathbf{0 . 1 9 6}$ & $(0.081)$ \\
$\mathbf{0 . 1 3 9}$ & $(0.034)$ & $\mathbf{0 . 3 1 7}$ & $(0.098)$ \\
$\mathbf{0 . 0 9 7}$ & $(0.028)$ & $\mathbf{0 . 1 8 7}$ & $(0.081)$ \\
$\mathbf{0 . 0 9 3}$ & $(0.033)$ & $\mathbf{0 . 1 9 9}$ & $(0.089)$ \\
$\mathbf{0 . 0 9 3}$ & $(0.037)$ & $\mathbf{0 . 2 2 1}$ & $(0.097)$ \\
$\mathbf{0 . 0 6 7}$ & $(0.032)$ & 0.124 & $(0.082)$ \\
$\mathbf{0 . 0 6 5}$ & $(0.034)$ & 0.071 & $(0.087)$ \\
$\mathbf{0 . 0 8 1}$ & $(0.035)$ & 0.136 & $(0.092)$ \\
$\mathbf{0 . 0 8 4}$ & $(0.034)$ & $\mathbf{0 . 1 7 8}$ & $(0.095)$ \\
0.046 & $(0.066)$ & $\mathbf{0 . 1 5 3}$ & $(0.088)$ \\
0.091 & $(0.079)$ & $\mathbf{0 . 3 3 6}$ & $(0.119)$ \\
0.019 & $(0.030)$ & 0.058 & $(0.070)$ \\
\hline 0.003 & & 0.027 & \\
\hline $\mathbf{0 . 0 7 4 1}$ & $(0.023)$ & $\mathbf{0 . 1 6 6}$ & $(0.055)$ \\
\hline $\mathbf{0 . 0 7 3}$ & $(0.034)$ & $\mathbf{0 . 1 2 5}$ & $(0.068)$ \\
\hline $\mathbf{0 . 0 9 8}$ & $(0.024)$ & $\mathbf{0 . 2 1 8}$ & $(0.062)$ \\
\hline 0.040 & $(0.032)$ & $\mathbf{0 . 1 3 9}$ & $(0.054)$ \\
\hline 0.580 & & 1.011 \\
\hline-0.708 & & 0.161 & \\
\hline & & & \\
\hline
\end{tabular}


B. Overconfidence in the signals of the core explanatory variables

Stock market returns

Consumption changes

Human capital changes

\begin{tabular}{|c|c|c|c|c|c|c|c|c|c|}
\hline & & & \\
\hline & $\begin{array}{l}\text { Overconfidence } \\
\left(\rho_{i k}\right)\end{array}$ & $\begin{array}{l}\text { Delta ratio } \\
\left(\delta_{i k} / \delta_{i k}^{b}\right)\end{array}$ & $t$ stat & $\begin{array}{l}\text { Overconfidence\# } \\
\left(\rho_{i k}\right)\end{array}$ & $\begin{array}{l}\text { Delta ratio } \\
\left(\delta_{i k} / \delta_{i k}^{b}\right)\end{array}$ & t stat & $\begin{array}{c}\text { Overconfidence\# } \\
\left(\rho_{i k}\right)\end{array}$ & $\begin{array}{l}\text { Delta ratio } \\
\left(\delta_{i k} / \delta_{i k}^{b}\right)\end{array}$ & $t$ stat \\
\hline UK & 0.004 & 0.281 & -1.12 & 0.004 & \begin{tabular}{|l}
$\mathbf{0 . 3 3 7}$ \\
\end{tabular} & -7.07 & 0.016 & 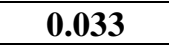 & -1.97 \\
\hline $\mathrm{NE}$ & -0.004 & 1.706 & 0.05 & 0.005 & 0.232 & -3.86 & 0.009 & 0.402 & -1.37 \\
\hline NW & -0.002 & 1.377 & 0.18 & 0.004 & 0.295 & -5.16 & 0.008 & 0.438 & -1.72 \\
\hline YH & 0.002 & 0.572 & -0.29 & 0.005 & 0.235 & -5.40 & 0.007 & 0.517 & -1.05 \\
\hline EM & 0.005 & 0.091 & -1.12 & 0.004 & 0.334 & -5.61 & 0.008 & 0.469 & -1.12 \\
\hline WM & 0.005 & 0.117 & -1.20 & 0.004 & 0.326 & -5.61 & 0.009 & 0.421 & -1.23 \\
\hline $\mathrm{E}$ & 0.005 & 0.151 & -1.74 & 0.003 & 0.434 & -3.90 & 0.008 & 0.537 & -0.65 \\
\hline $\mathrm{L}$ & 0.005 & 0.175 & -2.07 & 0.004 & 0.368 & -4.65 & 0.001 & 0.914 & -0.06 \\
\hline SE & 0.005 & 0.148 & -2.15 & 0.004 & 0.395 & -5.39 & 0.006 & 0.593 & -0.56 \\
\hline SW & 0.005 & 0.124 & -1.67 & 0.004 & 0.406 & -4.88 & 0.008 & 0.469 & -0.94 \\
\hline W & 0.001 & 0.757 & -0.12 & 0.005 & 0.249 & -4.61 & 0.049 & 0.300 & -0.97 \\
\hline SL & -0.010 & 2.710 & 0.26 & 0.005 & 0.247 & -3.85 & 0.037 & 0.270 & -1.72 \\
\hline NI & 0.008 & -0.507 & 1.71 & 0.004 & 0.361 & -2.41 & 0.014 & 0.322 & -0.52 \\
\hline All 12 Regions & 0.004 & 0.358 & -0.92 & 0.005 & 0.258 & -6.58 & 0.012 & 0.446 & -1.56 \\
\hline L, SE, SW, E & 0.005 & 0.152 & -2.17 & 0.004 & 0.391 & -5.47 & 0.007 & 0.590 & -0.67 \\
\hline Other England & 0.004 & 0.377 & -0.61 & 0.004 & 0.282 & -6.44 & 0.008 & 0.448 & -1.80 \\
\hline $\mathrm{W}, \mathrm{SL}, \mathrm{NI}$ & 0.016 & -1.800 & 1.11 & 0.004 & 0.281 & -4.22 & 0.033 & 0.291 & -1.56 \\
\hline
\end{tabular}


Table 3. Biased coefficients and unbiased coefficients

This table reports the effects of overconfidence biases on the regression coefficients in Panel A, the biased coefficients of property returns on the signals of the three core explanatory variables in Panel B, and the bias-free coefficients in Panel C for the 12 regions: North East (NE), North West (NW), Yorkshire and the Humber (YH), East Midlands (EM), West Midlands (WM), East (E), London (L), South East (SE), South West (SW), Wales (W), Scotland (SL) and Northern Ireland (NI). Panel A reports the regression results for the household prediction of $t+1$ property returns using signals available at time $t$. Panel B reports the unbiased coefficients of property returns on the signals, which are calculated using $\gamma_{i k}=\gamma_{i k}^{b_{p}} \frac{\operatorname{Var}\left(s_{k t}\right)-\rho_{i k}}{\operatorname{Var}\left(s_{k t}\right)}$ where $\gamma_{i k}^{b_{p}}$ and $\rho_{i k}$ are in panel A of Table 3 and panel B of Table 2, respectively.

A. Regression coefficients on noisy signals of the three core explanatory variables

\begin{tabular}{|c|c|c|c|c|c|c|c|c|c|c|c|c|}
\hline & NE & NW & YH & EM & WM & $\mathbf{E}$ & $\mathbf{L}$ & SE & SW & $\mathbf{W}$ & SL & NI \\
\hline \multirow{2}{*}{ constant } & 0.006 & 0.007 & 0.005 & 0.007 & 0.007 & 0.009 & 0.013 & 0.010 & 0.009 & 0.007 & $\mathbf{0 . 0 0 7}$ & 0.007 \\
\hline & $(0.003)$ & $(0.002)$ & $(0.003)$ & $(0.003)$ & $(0.002)$ & $(0.003)$ & $(0.003)$ & $(0.003)$ & $(0.002)$ & $(0.003)$ & $(0.002)$ & $(0.005)$ \\
\hline \multirow{2}{*}{ Noisy signal for stock returns } & -0.013 & -0.009 & -0.002 & 0.006 & 0.007 & 0.023 & 0.034 & 0.028 & 0.016 & -0.001 & -0.010 & -0.021 \\
\hline & $(0.011)$ & $(0.009)$ & $(0.011)$ & $(0.010)$ & $(0.008)$ & $(0.011)$ & $(0.011)$ & $(0.010)$ & $(0.009)$ & $(0.011)$ & $(0.008)$ & $(0.014)$ \\
\hline \multirow{2}{*}{ Noisy signal for consumption changes } & $\mathbf{0 . 8 3 2}$ & 0.899 & 1.093 & 1.138 & 1.030 & 1.094 & 1.134 & 1.184 & 1.056 & 0.989 & 0.581 & 0.766 \\
\hline & $(0.195)$ & $(0.169)$ & $(0.254)$ & $(0.217)$ & $(0.190)$ & $(0.167)$ & $(0.149)$ & $(0.148)$ & $(0.154)$ & $(0.243)$ & $(0.126)$ & $(0.251)$ \\
\hline \multirow{2}{*}{ Noisy signal for household income changes } & 0.188 & 0.173 & 0.098 & 0.039 & 0.027 & -0.084 & -0.203 & -0.142 & -0.045 & 0.062 & 0.152 & 0.100 \\
\hline & $(0.079)$ & $(0.088)$ & $(0.112)$ & $(0.082)$ & $(0.056)$ & $(0.090)$ & $(0.087)$ & $(0.081)$ & $(0.064)$ & $(0.085)$ & $(0.056)$ & $(0.114)$ \\
\hline
\end{tabular}

B. Estimation of the unbiased coefficients: free from overconfidence

\begin{tabular}{|c|c|c|c|c|c|c|c|c|c|c|c|c|}
\hline & NE & NW & YH & EM & WM & $\mathbf{E}$ & $\mathbf{L}$ & SE & SW & $\mathbf{W}$ & SL & NI \\
\hline constant & -0.006 & -0.005 & -0.006 & -0.004 & -0.004 & -0.003 & 0.001 & -0.002 & -0.002 & -0.006 & -0.004 & -0.005 \\
\hline Noisy signal for stock returns & -0.031 & -0.019 & -0.003 & 0.000 & 0.000 & 0.003 & 0.006 & 0.004 & 0.002 & -0.008 & -0.047 & 0.014 \\
\hline Noisy signal for consumption changes & 0.203 & 0.281 & 0.273 & 0.401 & 0.359 & 0.505 & 0.445 & 0.500 & 0.460 & 0.257 & 0.149 & 0.294 \\
\hline Noisy signal for household income changes & -0.045 & -0.059 & -0.111 & -0.128 & -0.122 & -0.212 & -0.477 & -0.273 & -0.170 & -0.055 & -0.030 & -0.059 \\
\hline
\end{tabular}


Table 4. Comparison of residential property returns

This table reports realized property returns, average posterior expected property returns free from overconfidence (calculated with the coefficients in Panel B of Table 3), and average posterior expected property returns affected by overconfidence (estimated with the coefficients biased by the overconfidence in Panel B of Table 2) for the UK and its 12 regions: North East (NE), North West (NW), Yorkshire and the Humber (YH), East Midlands (EM), West Midlands (WM), East (E), London (L), South East (SE), South West (SW), Wales (W), Scotland (SL) and Northern Ireland (NI). The numbers in the round brackets are standard errors of the average returns.

\begin{tabular}{ccccccccccccc} 
UK & NE & NW & YH & EM & WM & E & L & SE & SW & Wales & Scotland & NI \\
\hline Realized property returns & & & & & & & & & & & & \\
$1.50 \%$ & $1.35 \%$ & $1.45 \%$ & $1.35 \%$ & $1.56 \%$ & $1.47 \%$ & $1.57 \%$ & $1.82 \%$ & $1.62 \%$ & $1.59 \%$ & $1.36 \%$ & $1.27 \%$ & $1.22 \%$ \\
$(0.18 \%)$ & $(0.27 \%)$ & $(0.22 \%)$ & $(0.26 \%)$ & $(0.24 \%)$ & $(0.22 \%)$ & $(0.26 \%)$ & $(0.25 \%)$ & $(0.23 \%)$ & $(0.22 \%)$ & $(0.26 \%)$ & $(0.19 \%)$ & $(0.31 \%)$
\end{tabular}

Posterior expected property returns free from overconfidence

$\begin{array}{cccccccccccccc}1.03 \% & 0.77 \% & 0.91 \% & 0.77 \% & 1.04 \% & 1.00 \% & 1.17 \% & 1.31 \% & 1.17 \% & 1.18 \% & 0.84 \% & 0.80 \% & 0.93 \% \\ (0.05 \%) & (0.06 \%) & (0.05 \%) & (0.04 \%) & (0.06 \%) & (0.05 \%) & (0.07 \%) & (0.06 \%) & (0.06 \%) & (0.05 \%) & (0.03 \%) & (0.06 \%) & (0.05 \%)\end{array}$

Posterior expected property returns affected by overconfidence

$\begin{array}{cccccccccccccc}1.53 \% & 1.35 \% & 1.45 \% & 1.35 \% & 1.56 \% & 1.47 \% & 1.57 \% & 1.82 \% & 1.62 \% & 1.59 \% & 1.36 \% & 1.27 \% & 1.22 \% \\ (0.14 \%) & (0.12 \%) & (0.13 \%) & (0.15 \%) & (0.15 \%) & (0.14 \%) & (0.15 \%) & (0.15 \%) & (0.16 \%) & (0.14 \%) & (0.13 \%) & (0.09 \%) & (0.11 \%)\end{array}$


Table 5. Overconfidence in the lagged core explanatory variables

For households who use $x_{k t}$ as the noisy signal for $x_{k t+1}, s_{k t}$ is constructed assuming that the lagged core variables include information of its future value:

$1^{\text {st }}$ step: $x_{k t}=\alpha_{k}+\beta_{k} x_{k t+1}+\epsilon_{i k t}$ for $k=1, \ldots, K$.

$2^{\text {nd }}$ step: $S_{k t}=\frac{x_{k t}}{\beta_{i k}}-\frac{\alpha_{k}}{\beta_{k}}=x_{k t+1}+\varepsilon_{k t}$, where $\varepsilon_{k t}=\frac{\epsilon_{k t}}{\beta_{k}}$ for $k=1, \ldots, K$.

The ratios of deltas $\left(\delta_{i k t} / \delta_{i k t}^{b}\right)$ and the $t$ statistics for $\hat{\delta}_{i k t}-\hat{\delta}_{i k t}^{b}$ are calculated to investigate the household overconfidence about the noisy signals of factors: $x_{k t+1}=$ $\mu_{k}+\delta_{i k t} r_{i t+1}^{b}+e_{i k t+1}$ and $s_{k t}=\mu_{k}^{\prime}+\delta_{i k t}^{b} r_{i t+1}^{b}+e_{i k t+1}^{\prime}$, where $s_{k t}$ and $x_{k t+1}$ are the noisy signal at time $t$ and the realized factor value at time $t+1$ on factor $k$, respectively, and $r_{i t+1}^{b}$ is the realized property return. Stock market return reflects the returns of FTSE All Share index. Consumption change and human capital change represent changes in household consumption and changes in gross disposable household income, respectively. The 12 regions in the UK include North East (NE), North West (NW), Yorkshire and the Humber (YH), East Midlands (EM), West Midlands (WM), East (E), London (L), South East (SE), South West (SW), Wales (W), Scotland (SL) and Northern Ireland (NI).

\begin{tabular}{|c|c|c|c|c|c|c|c|c|c|c|c|c|c|c|c|c|c|c|}
\hline & \multicolumn{6}{|c|}{ Stock market returns } & \multicolumn{6}{|c|}{ Consumption changes } & \multicolumn{6}{|c|}{ Human capital changes } \\
\hline & \multicolumn{2}{|c|}{$\hat{\delta}_{i k t}$} & \multicolumn{2}{|c|}{$\hat{\delta}_{i k t}^{b}$} & \multirow{2}{*}{$\begin{array}{c}\text { Delta ratio } \\
0.035\end{array}$} & \multirow{2}{*}{$\begin{array}{l}t \text { stat } \\
-1.79\end{array}$} & \multicolumn{2}{|c|}{$\hat{\delta}_{i k t}$} & \multicolumn{2}{|c|}{$\hat{\delta}_{i k t}^{b}$} & \multirow{2}{*}{\begin{tabular}{|c|} 
Delta ratio \\
$\mathbf{0 . 2 7 3}$
\end{tabular}} & \multirow{2}{*}{$\begin{array}{l}t \text { stat } \\
-3.80\end{array}$} & \multicolumn{2}{|c|}{$\hat{\delta}_{i k t}$} & \multicolumn{2}{|c|}{$\hat{\delta}_{i k t}^{b}$} & \multirow{2}{*}{$\begin{array}{c}\text { Delta ratio } \\
0.015\end{array}$} & \multirow{2}{*}{$\begin{array}{l}t \text { stat } \\
-0.96\end{array}$} \\
\hline $\mathrm{UK}$ & 0.438 & $(0.262)$ & 12.362 & $(6.675)$ & & & 0.166 & $(0.024)$ & 0.610 & $(0.114)$ & & & 0.008 & $(0.046)$ & 0.547 & $(0.558)$ & & \\
\hline $\mathrm{NE}$ & 0.076 & $(0.180)$ & 6.058 & $(4.571)$ & 0.013 & -1.31 & 0.046 & $(0.018)$ & 0.179 & $(0.083)$ & 0.257 & -1.56 & 0.079 & $(0.028)$ & 0.519 & $(0.125)$ & 0.151 & -3.43 \\
\hline NW & 0.563 & $(0.220)$ & 4.547 & $(5.710)$ & 0.124 & -0.70 & 0.098 & $(0.022)$ & 0.326 & $(0.102)$ & 0.300 & -2.19 & 0.141 & $(0.034)$ & 0.510 & $(0.158)$ & 0.276 & -2.29 \\
\hline YH & 0.271 & $(0.184)$ & 7.389 & (4.699) & 0.037 & -1.51 & 0.063 & $(0.019)$ & 0.277 & $(0.084)$ & 0.228 & -2.48 & 0.096 & $(0.028)$ & 0.281 & $(0.102)$ & 0.343 & -1.74 \\
\hline EM & 0.086 & $(0.202)$ & 7.765 & (5.108) & 0.011 & -1.50 & 0.110 & (0.019) & 0.384 & $(0.090)$ & 0.286 & -2.99 & 0.093 & $(0.032)$ & 0.332 & $(0.151)$ & 0.280 & -1.55 \\
\hline WM & 0.135 & $(0.223)$ & 3.482 & (5.690) & 0.039 & -0.59 & 0.117 & $(0.021)$ & 0.468 & $(0.098)$ & 0.251 & -3.50 & 0.094 & $(0.037)$ & 0.406 & $(0.164)$ & 0.231 & -1.86 \\
\hline E & 0.219 & $(0.186)$ & 1.926 & $(4.765)$ & 0.114 & -0.36 & 0.113 & $(0.017)$ & 0.343 & $(0.083)$ & 0.331 & -2.69 & 0.067 & $(0.032)$ & 0.195 & $(0.181)$ & 0.342 & -0.70 \\
\hline $\mathrm{L}$ & 0.325 & $(0.197)$ & 15.001 & $(4.915)$ & 0.022 & -2.98 & 0.107 & $(0.019)$ & 0.353 & $(0.089)$ & 0.304 & -2.71 & 0.064 & $(0.034)$ & 0.358 & $(0.503)$ & 0.179 & -0.58 \\
\hline SE & 0.295 & $(0.210)$ & 5.043 & $(5.371)$ & 0.059 & -0.88 & 0.139 & $(0.019)$ & 0.462 & $(0.092)$ & 0.301 & -3.43 & 0.081 & $(0.034)$ & 0.233 & $(0.223)$ & 0.348 & -0.67 \\
\hline SW & 0.194 & $(0.217)$ & 3.523 & (5.547) & 0.055 & -0.60 & 0.135 & $(0.020)$ & 0.492 & $(0.094)$ & 0.275 & -3.69 & 0.084 & $(0.034)$ & 0.363 & $(0.161)$ & 0.230 & -1.69 \\
\hline W & 0.263 & $(0.185)$ & 3.169 & (4.746) & 0.083 & -0.61 & 0.060 & $(0.019)$ & 0.277 & $(0.085)$ & 0.217 & -2.50 & 0.047 & $(0.066)$ & 2.470 & (2.941) & 0.019 & -0.82 \\
\hline SL & 0.410 & $(0.261)$ & 17.767 & $(6.558)$ & 0.023 & -2.64 & 0.072 & $(0.027)$ & 0.206 & $(0.122)$ & 0.352 & -1.06 & 0.092 & $(0.079)$ & 4.018 & $(2.279)$ & 0.023 & -1.72 \\
\hline NI & 0.341 & $(0.154)$ & 2.337 & (3.982) & 0.146 & -0.50 & 0.048 & $(0.016)$ & 0.139 & $(0.073)$ & 0.344 & -1.23 & 0.018 & $(0.030)$ & 0.269 & $(0.271)$ & 0.067 & -0.92 \\
\hline Average $\mathrm{R}^{2}$ & 0.014 & & 0.014 & & & & 0.139 & & 0.086 & & & & 0.034 & & 0.028 & & & \\
\hline
\end{tabular}


Table 6. Overconfidence in consumption and human capital changes with regional labour income

This table is a replication of Table 2 when regional labour income (average weekly earnings of full-time employees) is used instead of regional gross disposable household income for human capital. Regional labour income before 1997 is replaced with gross disposable household income because of restriction of the labour income data. The results of stock returns are not reported because they are not affected by different proxies for human capital. The 12 regions in the UK include North East (NE), North

West (NW), Yorkshire and the Humber (YH), East Midlands (EM), West Midlands (WM), East (E), London (L), South East (SE), South West (SW), Wales (W), Scotland (SL) and Northern Ireland (NI).

\begin{tabular}{|c|c|c|c|c|c|c|c|c|c|c|c|c|}
\hline \multirow[b]{3}{*}{ UK } & \multicolumn{6}{|c|}{ Consumption changes } & \multicolumn{6}{|c|}{ Human capital changes } \\
\hline & \multicolumn{2}{|c|}{$\hat{\delta}_{i k}$} & \multicolumn{2}{|c|}{$\hat{\delta}_{i k}^{b}$} & \multirow{2}{*}{$\begin{array}{c}\text { Delta ratio } \\
\mathbf{0 . 3 2 5}\end{array}$} & \multirow{2}{*}{$\begin{array}{l}\text { t stat } \\
-7.27\end{array}$} & \multicolumn{2}{|c|}{$\hat{\delta}_{i k}$} & \multicolumn{2}{|c|}{$\hat{\delta}_{i k}^{b}$} & \multirow{2}{*}{$\begin{array}{c}\text { Delta ratio } \\
0.226\end{array}$} & \multirow{2}{*}{$\begin{array}{l}\mathrm{t} \text { stat } \\
-0.91\end{array}$} \\
\hline & 0.166 & $(0.024)$ & 0.512 & $(0.041)$ & & & 0.049 & $(0.055)$ & 0.215 & $(0.175)$ & & \\
\hline $\mathrm{NE}$ & 0.046 & $(0.019)$ & 0.214 & $(0.036)$ & 0.214 & -4.19 & 0.093 & $(0.089)$ & 0.226 & $(0.197)$ & 0.410 & -0.62 \\
\hline NW & 0.098 & $(0.022)$ & 0.331 & $(0.041)$ & 0.295 & -4.96 & 0.079 & $(0.079)$ & 0.335 & $(0.194)$ & 0.237 & -1.22 \\
\hline YH & 0.063 & $(0.019)$ & 0.275 & $(0.034)$ & 0.229 & -5.45 & 0.065 & $(0.063)$ & 0.323 & $(0.159)$ & 0.203 & -1.50 \\
\hline EM & 0.110 & $(0.019)$ & 0.335 & $(0.035)$ & 0.327 & -5.60 & 0.085 & $(0.086)$ & 0.294 & $(0.201)$ & 0.289 & -0.96 \\
\hline WM & 0.117 & $(0.022)$ & 0.373 & $(0.039)$ & 0.314 & -5.79 & 0.065 & $(0.082)$ & 0.206 & $(0.200)$ & 0.318 & -0.65 \\
\hline E & 0.113 & $(0.017)$ & 0.276 & $(0.035)$ & 0.410 & -4.21 & -0.017 & $(0.073)$ & 0.023 & $(0.175)$ & -0.722 & -0.21 \\
\hline $\mathrm{L}$ & 0.107 & $(0.019)$ & 0.304 & $(0.036)$ & 0.353 & -4.85 & 0.023 & $(0.088)$ & 0.053 & $(0.197)$ & 0.440 & -0.14 \\
\hline SE & 0.139 & $(0.019)$ & 0.360 & $(0.036)$ & 0.386 & -5.42 & 0.039 & $(0.080)$ & -0.067 & (0.191) & -0.583 & 0.51 \\
\hline SW & 0.135 & $(0.020)$ & 0.361 & $(0.038)$ & 0.375 & -5.28 & -0.003 & $(0.074)$ & 0.200 & $(0.185)$ & -0.017 & -1.02 \\
\hline $\mathrm{W}$ & 0.060 & $(0.019)$ & 0.249 & $(0.036)$ & 0.242 & -4.68 & 0.030 & $(0.080)$ & 0.175 & (0.184) & 0.172 & -0.72 \\
\hline SL & 0.072 & $(0.027)$ & 0.309 & $(0.052)$ & 0.234 & -4.04 & 0.076 & $(0.104)$ & -0.009 & $(0.217)$ & -8.242 & 0.35 \\
\hline NI & 0.048 & $(0.016)$ & 0.128 & $(0.033)$ & 0.376 & -2.18 & -0.022 & $(0.102)$ & -0.009 & $(0.217)$ & 2.426 & -0.05 \\
\hline
\end{tabular}


Figure 1. Core explanatory variables and their noisy signals

This figure shows stock market returns, consumption changes, and household income changes and their noisy signals obtained from the four steps described in the empirical test section. Chart $\mathrm{C}$ shows UK household income changes rather than individual regional income changes for convenience.

\section{A. Stock marekt returns}

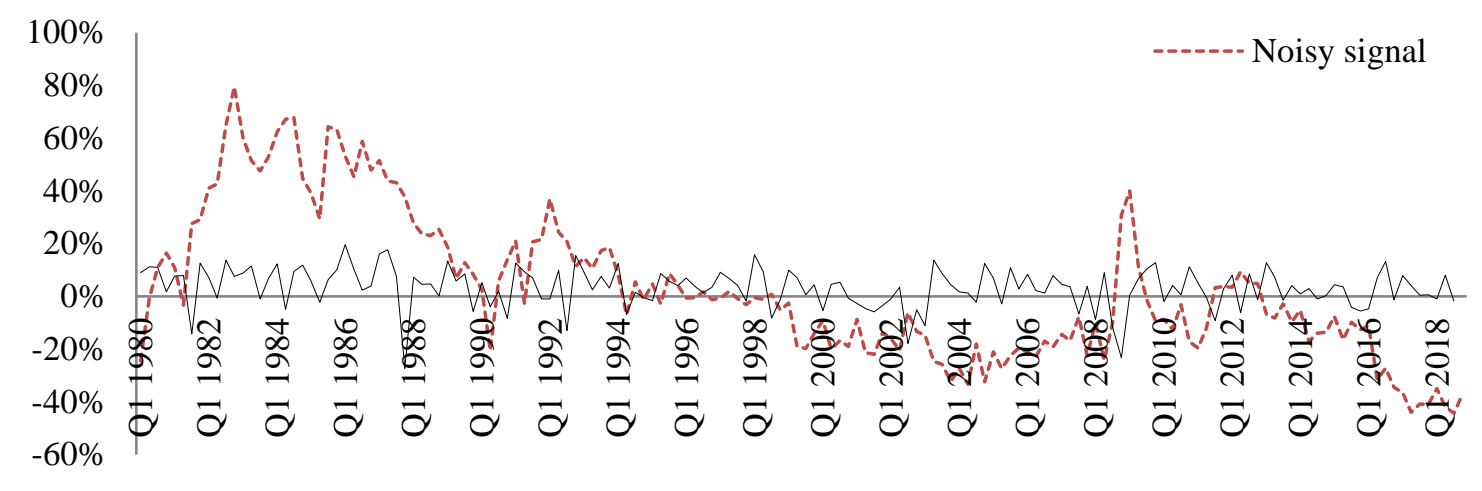

\section{B. Consumption changes}

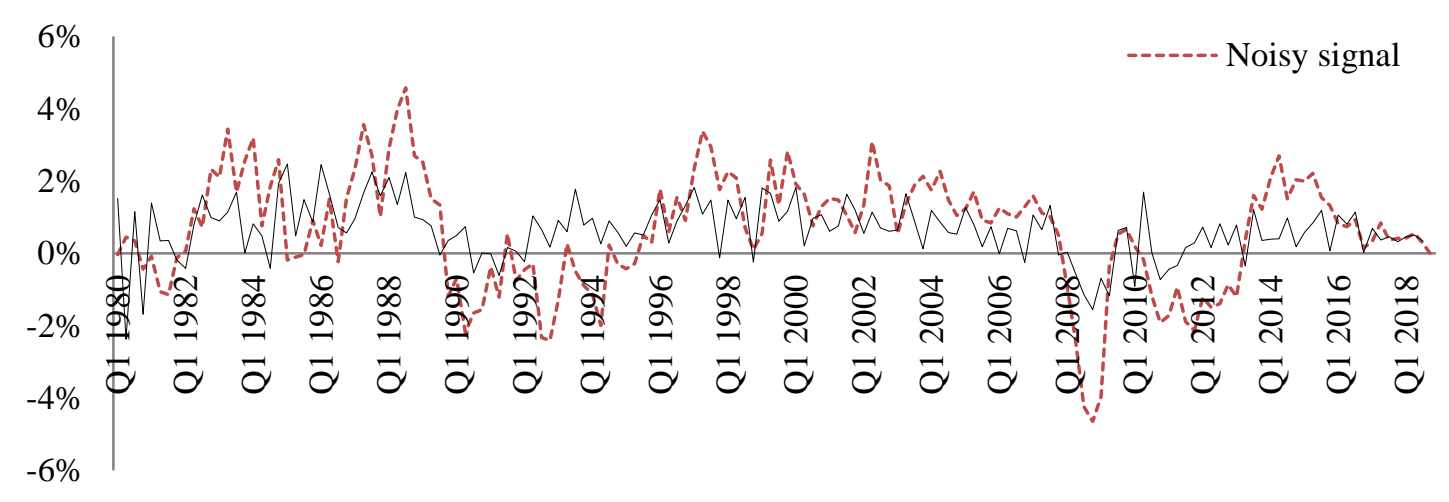

\section{Human capital changes (UK)}

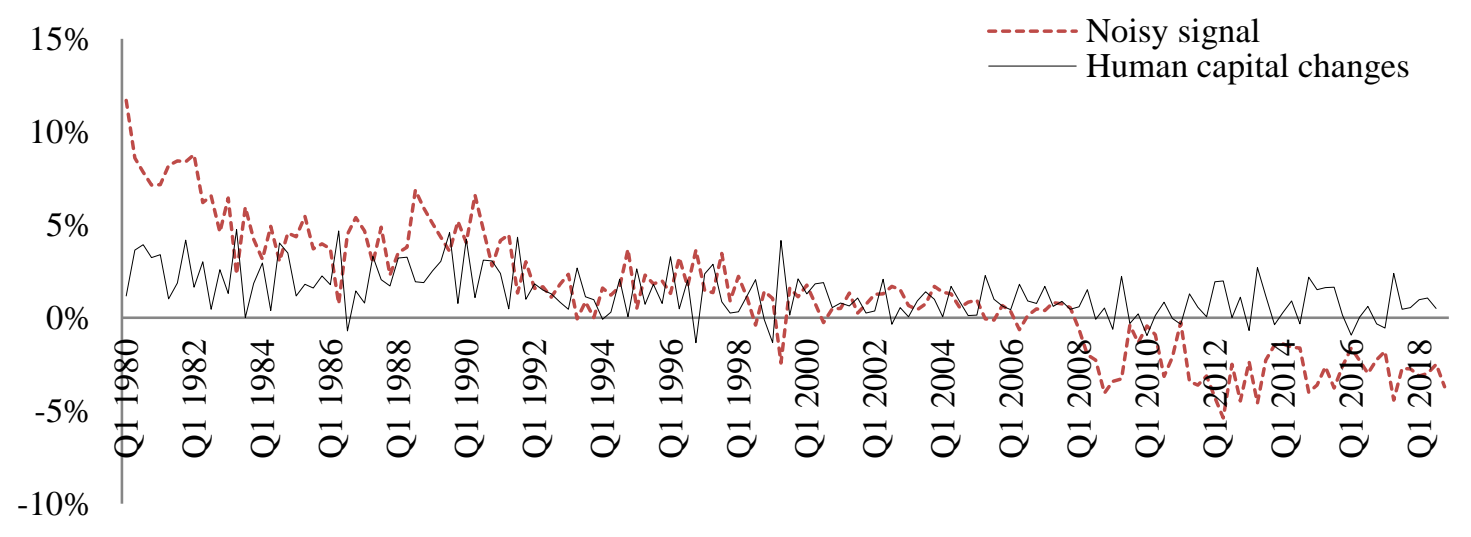


Figure 2. Expected property return bias by household overconfidence

Biases in the expected property returns are calculated by the difference between the property returns predicted by posterior expectations of the three core variables and the property returns predicted without overconfidence for the 12 regions in the UK: North East (NE), North West (NW), Yorkshire and the Humber (YH), East Midlands (EM), West Midlands (WM), East (E), London (L), South East (SE), South West (SW), Wales (W), Scotland (SL) and Northern Ireland (NI)..

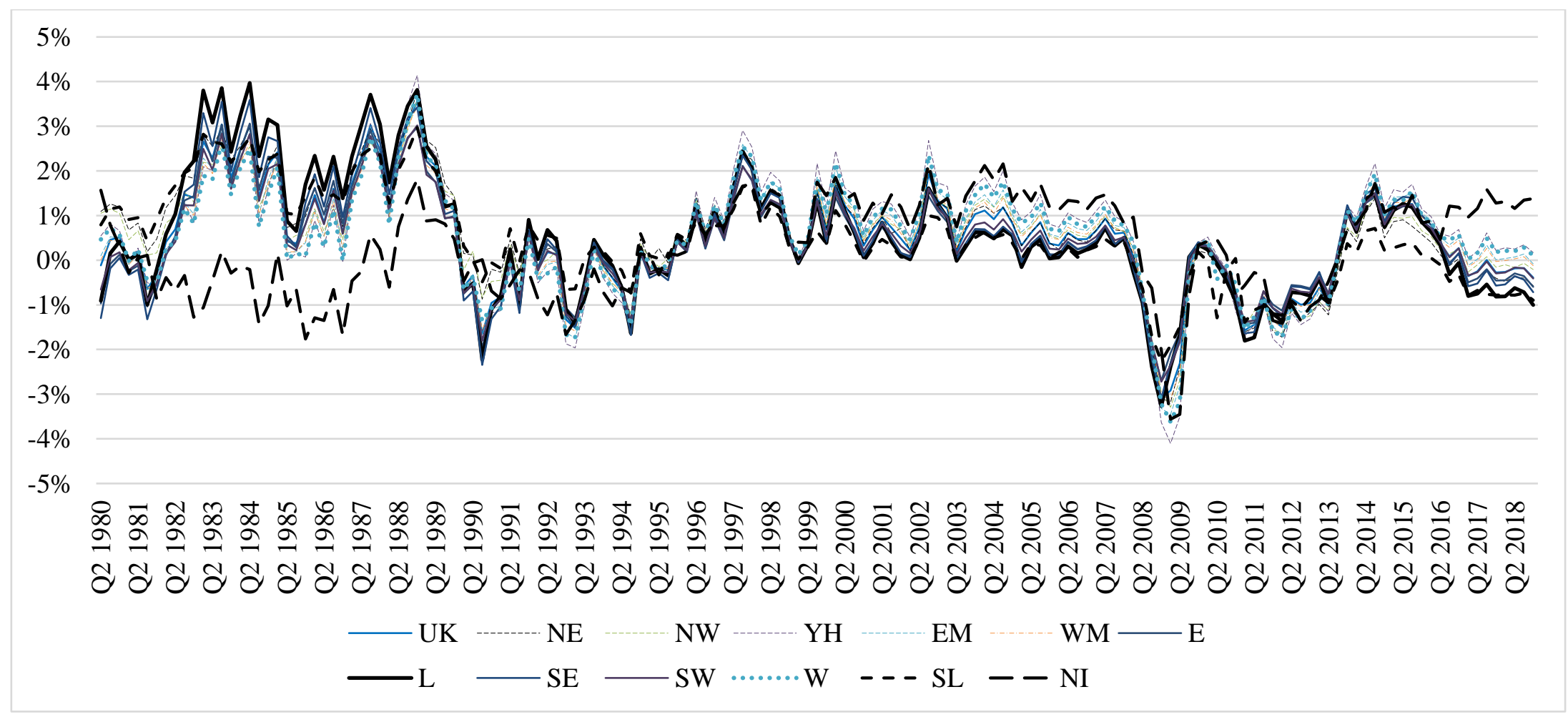

